JGOSS

14,3

\section{8}

Received 25 July 2020

Revised 8 December 2020

1 April 2021

Accepted 13 April 2021

\title{
Application of fuzzy TOPSIS framework for selecting complex project in a case company
}

\author{
Ahm Shamsuzzoha
}

Department of Production, University of Vaasa, Vaasa, Finland

Sujan Piya

Department of Mechanical and Industrial Engineering, Sultan Qaboos University, Muscat, Oman, and

Mohammad Shamsuzzaman

Department of Industrial Engineering and Engineering Management, University of Sharjah, Sharjah, United Arab Emirates

\begin{abstract}
Purpose - This study aims to propose a method known as the fuzzy technique for order preference by similarity to ideal solution (fuzzy TOPSIS) for complex project selection in organizations. To fulfill study objectives, the factors responsible for making a project complex are collected through literature review, which is then analyzed by fuzzy TOPSIS, based on three decision-makers' opinions.

Design/methodology/approach - The selection of complex projects is a multi-criteria decision-making (MCDM) process for global organizations. Traditional procedures for selecting complex projects are not adequate due to the limitations of linguistic assessment. To crossover such limitation, this study proposes the fuzzy MCDM method to select complex projects in organizations.

Findings - A large-scale engine manufacturing company, engaged in the energy business, is studied to validate the suitability of the fuzzy TOPSIS method and rank eight projects of the case company based on project complexity. Out of these eight projects, the closeness coefficient of the most complex project is found to be 0.817 and that of the least complex project is found to be 0.274 . Finally, study outcomes are concluded in the conclusion section, along with study limitations and future works.

Research limitations/implications - The outcomes from this research may not be generalized sufficiently due to the subjectivity of the interviewers. The study outcomes support project managers to optimize their project selection processes, especially to select complex projects. The presented methodology can be used extensively used by the project planners/managers to find the driving factors related to project complexity.

Originality/value - The presented study deliberately explained how complex projects in an organization could be select efficiently. This selection methodology supports top management to maintain their proposed projects with optimum resource allocations and maximum productivity.
\end{abstract}

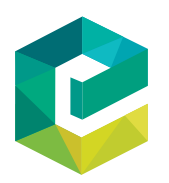

Journal of Global Operations and Strategic Sourcing Vol. 14 No. 3,2021 pp. $528-566$

pp. 528-566
Emerald Publishing Limited 2398-5364

DOI 10.1108/JGOSS-07-2020-0040
Keywords Fuzzy TOPSIS, Case study, Multi-criteria decision-making, Both, Expert opinions, Complex projects selection

Paper type Case study

(C) Ahm Shamsuzzoha, Sujan Piya and Mohammad Shamsuzzaman. Published by Emerald Publishing Limited. This article is published under the Creative Commons Attribution (CC BY 4.0) license. Anyone may reproduce, distribute, translate and create derivative works of this article (for both commercial and non-commercial purposes), subject to full attribution to the original publication and authors. The full terms of this license may be seen at http://creativecommons.org/licences/by/4.0/legalcode 


\section{Introduction}

Due to the competitive business environment, innovative and complexity-free projects are expected for organizational success (Mahmoud-Jouini et al., 2016; Beste et al., 2020; Wang et al., 2020). All organizations would like to run a project that finishes with the desired quality standards, within the given time limits and within the predetermined budgets (Khadem et al., 2018). However, in real practice, it is claimed that most of the projects do not reach their objectives due to several reasons such as poor planning, poor execution, poor coordination, the unclear scope of work and conflicts between team members, (Cui et al., 2019; Westfall, 2020). Therefore, successful project management mainly depends on the way out to overcome these issues, which hinders the successful execution of the project. Moreover, apart from these aforementioned reasons, it has been identified that one primary reason for the project failure is due to the poor decision to project selection. Specifically, it is necessary to understand the complexity level involved in the project. Nevertheless, it is also required to take a proper action plan to overcome the project complexity., All such measures are important for the decision-makers to take into account while selecting the projects (Kermanshachi et al., 2016; Bjorvatn and Wald, 2018). Therefore, the responsibilities put on the shoulders of the decision-makers of the organizations handling the projects are huge and require them to develop special decision-making frameworks, policies and procedures for complex project selection (Kermanshachi et al., 2020).

In organizations, the first step to manage a project is to make a decision on whether to allocate extra resources to a project or not. Moreover, project management often needs to make decisions to select projects based on the available opportunities and complexities associated with the project. There is no universally accepted definition of a complex project (Bakhshi et al., 2016). According to White et al. (2016), a complex project consists of complicated, uncertain, chaotic or even all three conditions that occurred. Vidal et al. (2011a, 2011b) defined a complex project as a project that makes it difficult to understand, foresee and keep under control its overall behavior. According to Hatch and Cunliffe (2012), project complexity has consisted of many different elements with multiple interactions and feedback loops between elements. Damayanti et al. (2019) identified the complex project as a matter related to the relationship of activities, processes and entities with varying levels of linearity and uncertainty. Project complexity becomes an increasingly important issue and attracts more attention to the organization (San Cristobal, 2017; Bjorvatn and Wald, 2018). In today's competitive market, successful projects enable managers to survive and prosper.

Selection of a successful project is not an easy task, and therefore it is necessary to investigate new tools and techniques to ensure successful projects. For a successful project, it is needed to find out the complex projects that need special attention. To find out the complex projects, one solution is to look for the attributes or factors, which are responsible for making any project complex. These factors are then can be analyzed with support from the MCDM method and compare the identified factors responsible for the project's complexity of an organization (Beldek et al., 2020). However, in real life, the evaluation and selection of complex projects depend on various factors, which are mostly subjective in nature. The importances or weights of these factors are usually expressed in linguistic terms rather than numerical values. Such linguistic terms are complex in nature and are difficult to interpret and often fail to bring the necessary conclusion in making a final decision. To efficiently resolve the ambiguity of such linguistic terms and convert the terms to a more understandable format, the fuzzy set theory then may be adopted to solve poorly defined MCDM issues (Buyukozkan and Gocer, 2017).

This study adopted a fuzzy technique for order preference by similarity to the ideal solution (TOPSIS) method with the objective to select complex projects. To implement this

Application of fuzzy TOPSIS framework 
JGOSS 14,3

method, all the identified criteria and their weights are converted to fuzzy numbers. In general, projects are consisted of several conflicting criteria, and hence very problematic to rank them. In such a situation, the MCDM method can be applied successfully. In this study, the most complex projects are selected after ranking them by using the fuzzy TOPSIS method (Kumar et al., 2019). Usually, organizational managers select projects, which are hopefully, secure their contracts. Secure and successful projects enable managers to survive and prosper. Nevertheless, selecting an appropriate project is not a simple task but it often becomes costly. Many companies spend costly resources on unsuccessful projects (Kerzner and Thamhain, 1986). A manager's goal is to manage successful projects and not to approve the project proposals only. Based on such a situation, this research study identified two research questions $(R Q s)$ as stated below:

\section{$R Q 1$. What are the common factors responsible for making a project complex?}

$R Q 2$. How to analyze the collected factors to identify the most complex project by using the Fuzzy-MCDM method?

The rest of the paper is presented as follows: Section 2 reviews the existing literature on project complexity, associated factors for project complexity and application of fuzzy TOPSIS method used in MCDM. Section 3 presents the study methodology, while Section 4 illustrates a numerical analysis, where the deployment of the fuzzy TOPSIS method within a case company is demonstrated. Section 5 explains the study outcomes and overall managerial implications of the study. Finally, Section 6 concludes the study outcomes along with study limitations and future research directions.

\section{Literature review}

In the case of managing a project, it is critical to make a decision on whether a project is complex or not and often the decision depends on available resources. Therefore, it is important for managers to select projects, which have a higher possibility of success. Managers must focus their efforts to identify and selecting less complex projects as much as possible. To identify the factors, which are responsible to make a project complex, this study was considered the published literature from various data sources such as Google scholar, science direct, Scopus, research gate, web of science, Wiley, springer link, Mendeley and endnote and was related to project management topic mostly during the year 2014-2020. During the literature survey, this study was considered keywords such as complex project, challenges in the project, successful project, project risk and project failure. All such keywords are used to identify the factors responsible to make any project complex. In addition, in this study, several industries such as manufacturing, service, automotive, electronic, mining and oil and gas, are considered to identify the project's complexity factors. It is noticed from this study that most of the identified factors are common to the allindustrial sectors.

As project selection is a critical decision to managers, this area of research has been studied by many researchers. For instance, Han et al. (2019) used a multi-criteria decisionmaking process to project selection, whereas, Hamdan et al. (2019) conducted opinion surveys of contractors to investigate delay factors in electrical installation projects. Venkatesh et al. (2019) presented a supply partner selection framework using a multi-criteria decision-making model based on verified criteria attributes. Ma et al. (2020) studied multicriteria project portfolio selection based on sustainability. Multi-criteria project selection based on uncertainty and risk are studied too (Jafarzadeh et al., 2018; Davoudabadi et al., 2019; Ma et al., 2020; Pramanik et al., 2020; Dandage et al., 2021). In the case of the complex 
project selection method, it is essential to find out the factors that affect projects, complexity (Dobrovolskiene and Tamosiuniene, 2016; Floyd et al., 2017; Park et al., 2018; Mishra and Mahanty, 2019). It is often cumbersome and uncertain to determine the weight of the factors that are responsible for project complexities. Such uncertainty of weight of the factors influences the quality of project selection. In this uncertain situation, the Fuzzy set theory might be used as a useful tool (Liang et al., 2019; Yazdi et al., 2020; Ma et al., 2020).

In literature, many studies have been conducted to find the reasons for complex projects (Frini and BenAmor, 2015; Arditi et al., 2017; Rumeser and Emsley, 2019; Schultz et al., 2019; Chowdhury et al., 2020; Trinh and Feng, 2020). However, it was not noticed so many, where responsible factors of project complexities are analyzed rigorously. In addition, identification of the factors was mostly collected from various literature surveys and less focused on experts' opinions. Moreover, the factors were collected for a specific region or industry, which may not generalize the study results to the wider audience. Furthermore, the identified factors were analyzed using various MCDM and not with fuzzy TOPSIS method which offers comparatively better results (Singh et al., 2018; Gupta et al., 2019; Beldek et al., 2020). Considering mentioned limitations, this study identified the project complexity factors through both literature survey and experts' opinions, which authenticate the study outcomes to the wider audience. In addition, this study analyzed the identified factors by using the Fuzzy TOPSIS method that also offers extra credibility to the study outcomes.

\subsection{Factors affecting the project complexity}

To identify the complex projects, at first, it is necessary to identify the factors, which are responsible for such complexity. These factors are known as driving factors and can be identified by reviewing existing literature and experts' opinions from organizations (Piya et al., 2019). Such identified factors are to be analyzed to select complex projects accordingly. Based on the requirement to identify the complex projects, several factors are collected from the literature review as presented in Table 1. The relationships between the identified factors with the project complexity are also presented in the Table. Each of the identified factors is defined briefly thereafter.

2.1.1 Stakeholders. According to PMI (2013) project stakeholder refers to, "an individual, group or organization, who may affect, be affected by or perceive itself to be affected by a decision, activity or outcome of a project." Examples of project stakeholders can be a sponsor of a project, project leader, resource managers, project customers, consultants, team members, etc. In general, more stakeholders create more exchange of information among themselves that create project complexity.

2.1.2 Size. Size of a project can be considered as an important factor that makes a project complex. Generally, a larger project size is much more complex than a smaller size project. The size of the project depends on the organizational structure and its interrelated elements.

2.1.3 Interdependencies. A project can be more complex if it is dependent on other projects to be executed. Usually, it is difficult to find a project that operates individually and does not depend on other projects.

2.1.4 Technology and tools. In general, up-to-date technology and tools expedite the project execution process, however, too much technology and tools may often create complexity. The adaptation of technology and tools are dependent on the variety of tasks within a project and the required level of specialization in each of them.

2.1.5 Management decisions. Management commitment, support and decision are crucial for the successful implementation of the project (Piya et al., 2020a, 2020b). A project can be complex or simple based on the management decision. It is considered an important factor to make the project simple or complex. Management decisions are dependent on the 


\section{JGOSS 14,3}

\section{2}

Size

Interdependencies

Jafarzadeh et al. (2018) and Al Zaabi and Bashir (2020)

Technology and tools

Tafi (2013); Poveda-Bautista et al. (2018) and Contractor (2018)

Management decisions

Cultural diversity

Kermanshachia et al. (2016), Ahmadi et al. (2017); Rumeser and Emsley (2019) and Schultz et al. (2019)

Variety (2020) Morris (2013) and Stretton (2017, 2019)

Resources and capability

Darcy et al. (2014); Fores and Camison (2016); Woschke et al. (2017), Nguyen et al. (2019) and Sharma and Naude (2021)

Uncertainty

Table 1.

List of factors that drive project complexity
Relation to project complexity

Works concerned with sustainable project selection, considering simultaneously the economic benefits, the environmental impacts and the decision-maker preferences

The size of the project affects complexity and reduces project management performance. This project size also influences project management The study proposed projects interdependencies between prioritization and uncertainty, which contributes toward project complexity

Proper technology and tools can be helpful to measure and eliminate project complexity

It is noticed that magnitude of change orders from management impacts project execution and complexity

Cultural diversity significantly influences the project complexity

Representation of a variety of contexts affects project management. It is essential to sort out who should be involved and in what capacities to effectively managing projects

Resource scarcity (e.g. human resource scarcity, financial resource scarcity, etc.) among companies affects the project innovation performance and increases the complexity

An investigation of the common causes of project delays is identified and prioritized based on the simple ranking methods and considering uncertainty in projects Efficient information exchange among projects can be one of the major enabling factors to achieve a successful project The level of policy incentives and regulations affect the effectiveness of any projects' implementation, confirming the adequacy of the offered methods and identifies various measures to ensure the project's success

project's stakeholders such as partners, suppliers and available tools and techniques. The on-time and efficient decision can simplify a project a lot.

2.1.6 Cultural diversity. Due to cultural variations between countries, managers often deal with projects differently. Globalization boots project complexity due to higher mobility, hierarchy, higher dynamics and erosion of boundaries. In such a perspective, cultural diversity plays a crucial role in determining the complexity of a project. 
2.1.7 Variety. When different projects are executed together, it creates complexity. More varieties initiate' added complexities in projects. More amount of tasks and services contribute to project complexity.

2.1.8 Resources and capability. Scarcity of required resources resembles a complex project. Sufficient resources and added capabilities contribute toward eliminating or lower the project complexity.

2.1.9 Uncertainty. Uncertainty of necessary elements such as resources, schedules, constraints, goals and methods creates a complex project. More level of uncertainty creates an increased level of project complexity.

2.1.10 Information exchange. To execute a project efficiently, continuous information exchange among project stakeholders is necessary. During project execution, professionals contribute to sharing information. To avoid project complexity, it is necessary to maintain real-time information exchange between project stakeholders.

2.1.11 Laws and regulations. Due to changes in laws and regulations, an institutional complexity can emerge in a project (Bosch-Rekveldt et al., 2011; He et al., 2015). Even if the laws and regulations are not changing, they are able to create conflict in a project, for instance when a project is the first to implement or execute a norm or when there are no laws, etc (Li et al., 2015; Floricel et al., 2016).

\subsection{Methods to analyze the identified factors to select a complex project}

Selection of complex projects enables managers to use their costly resources optimally with the possibility of successful projects. In organizations, the selection of projects is generally organized through a team of decision-makers following pre-specified guidelines. The decision-makers, within the group, select the projects according to their experience and skills. In this way, the sorting of complex projects is done based on the decision-makers' scores of pre-defined criteria. Fuzzy logic can be applied efficiently in such type of selection method for complex projects.

Various researchers used different tools and techniques to analyze the identified factors responsible for making the project complex. For example, Tan et al. (2010) used the TOPSIS method to select the construction project with the identified factors. Prascevic and Prascevic (2017) applied the fuzzy-analytic hierarchy process (AHP) method to rank and select alternates in managing projects. Han et al. (2019) used a multi-criteria project selection based on fuzzy-AHP and TOPSIS methods. The fuzzy TOPSIS method is very much efficient and popular for solving such multi-criteria decision-making processes and adopted in different organizations (Sadi-Nezhad, 2017; Prascevic and Prascevic, 2017; Han et al., 2019). To prioritize and select a project, Shaygan and Testik (2019) used a fuzzy-AHP based methodology.

Sadi-Nezhad (2017) presented a survey for project selection by considering the integration of TOPSIS and AHP/analytic network process (ANP). Pramanik et al. (2020) proposed integrated Shannon entropy and fuzzy techniques for managing uncertainty during project selection. Büyüközkan et al. (2017) implemented combined Intuitionistic Fuzzy ANP (IF-ANP) to analyze the criteria weights and Intuitionistic Fuzzy DecisionMaking Trial and Evaluation Laboratory (IF-DEMATEL) approach for evaluating partner for customer relationship management. Yalcin et al. (2019) proposed IF-DEMATEL and IFTOPSIS methods to select research and development projects.

As stated above, all the available MCDM approaches are focused mostly to select the project, partner, supplier, etc. However, in the literature, no research has been found to use the MCDM approach to select a complex project. To fulfill such a research gap, a fuzzy
Application of fuzzy TOPSIS framework 
JGOSS 14,3

TOPSIS method is adopted to categorize and select the most complex projects in organizations.

\subsection{Fuzzy technique for order preference by similarity to the ideal solution method}

Selection of a complex project remains a critical business issue in today's competitive business domain. There are too many factors involved in this selection process such as financial, technical, social and risk factors. It is not an easy task to decide a project based on minimizing uncontrollable factors and maximizing controllable factors. In this MCDM problem, the fuzzy approach can be a useful guideline to evaluate project selection (Gupta et al., 2019; Beldek et al., 2020). Fuzzy TOPSIS is also a multi-criteria technique that has been widely used due to its clear methodology and easily programmable computation procedure (Singh et al., 2018). TOPSIS method is introduced by Hwang and Yoon in the year 1981 (Tzeng and Huang, 2011). It is used to choose the best alternate considering multiple criteria. The popularity of the TOPSIS method can be measured by its application in various disciplines to solve MCDM issues (Du et al., 2014; Biswas et al., 2016; Fei et al., 2016; Sun et al., 2017; Chukwumaobi et al., 2020). TOPSIS method is considered one of the MCDM methods, where fuzzy numbers are used to solve problems involving human judgment and vagueness (Kumar et al., 2019). In the past two decades, several methods have been developed which integrates TOPSIS with fuzzy logic that can be successfully implemented for solving group decision-making problems (Singh et al., 2018; Gupta et al., 2019).

The main idea of TOPSIS is to select the alternate based on the distance from the ideal solutions. The drawback of traditional TOPSIS is that it uses the crisp value in the identification of the best alternate (Rajak and Shaw, 2019). However, there are many instances where the crisp data are not adequate to model a real-life situation, especially when the decision-making process involves human opinion. Under such a situation, the decision is to be made by taking into account uncertainty and vagueness. Therefore, instead of giving judgment in the form of a single crisp value, the decision-maker may evaluate the problem based on the interval judgment and using the linguistic term (Yang and Hung, 2007; Kannan et al., 2009). Many researchers have adopted fuzzy set theory in TOPSIS using the linguistic term to handle vagueness and deal with imprecise data (Kharat et al., 2019). The linguistic terms from decision-maker are interpreted in various forms of fuzzy numbers such as triangular (Kannan et al., 2013; Noktehdan et al., 2020), trapezoidal (Ganesan and Veeramani, 2006; Duzce, 2015), quadrilateral (Kumar et al., 2021) and Gaussian (Sahin and Yip, 2017). The use of a specific type of fuzzy numbers is dependent on the nature and characteristics of the identified problems and their ultimate nature of solutions. For instance, the triangular membership function is the simplest one and is widely applied to express linguistic terms (Pedrycz, 1994; Chen, 2000).

Many techniques are available for the evaluation and ranking of alternates with multiple criteria. Each of the techniques has its own advantages and limitations over others. Fuzzy TOPSIS is one of the widely used multi-criteria decision-making techniques. The advantage of Fuzzy TOPSIS is that it is simple in the computational procedure, easy to represent human preferences and allows explicit trade-offs between multiple criteria (Kannan et al., 2013). In addition, the technique is classified as a compromising model, with the notion that no ideal solution exists, but a solution with optimal values on all criteria is possible to accomplish. Therefore, in this paper, Fuzzy TOPSIS with a triangular membership function is used in a quest to select a complex project. 


\section{Study methodology}

Project complexity can be measured based on the analysis of a set of factors. However, before measuring the level of complexity, it is required to identify the factors that are responsible to project complexity. In this research, at first, 11 factors were identified based on the rigorous literature review and expert's opinions. These factors were presented in Table 1. In literature, there are several MCDM approaches such as min-max, max-min, ELECTRE, PROMETHEE, TOPSIS, fuzzy TOPSIS, compromise programming, AHP, fuzzy AHP, data envelopment analysis and goal programming. All such approaches can be used for comparing and prioritizing multiple alternates and finally selecting the best-fit choice (Sener et al., 2018). Among these techniques, fuzzy decision-making techniques have been attracting growing attention to getting solutions that contain unclear, incomplete information and linguistic variables (Kahraman et al., 2015; Kumar et al., 2019). Usually, fuzzy sets theory in the decision-making process is used when decision-makers have to make decisions with uncertain and ambiguous data (fuzzy data) (Erdin and Akbaş, 2019). Moreover, the application of fuzzy sets theory has significant supports for MCDM problems and contributes to the relative priorities of fuzzy numbers rather than precise numbers and has become one of the most suitable fields for using this theory (Yang and Hung, 2007).

This study adopted fuzzy triangular numbers in the MCDM method to allow the use of linguistic variables with respect to a numerical outcome that can be used to assess the best option among alternates, which are based on predefined criteria. The numerical outcome contributes to achieving effective results through quantifying the uncertain data. The major logic to choose the fuzzy triangular number rather than other available numbers is its inherent simplicity and ease to interpret the linguistics variables as mostly used by the experts. The fuzzy triangular numbers are extensively used by the researchers work in MCDM models due to their simple intuitiveness and calculation to performance measurement (Pedrycz, 1994; Vinodh and Devadasan, 2011; Koohathongsumrit and Meethom, 2021). In the case of a questionnaire survey, where the decision is mainly based on experts opinions, fuzzy triangular numbers are proved as efficient to calculate and required less time to get the solution successfully (Alkhatib, 2017; Patil et al., 2020; Jaukovic et al., 2020; Lam et al., 2021).

Furthermore, to analyze projects with respect to the identified factors, this study adopted a fuzzy TOPSIS method due to the uncertainty and vagueness associated with the understanding of and analyzing these factors. To demonstrate the working mechanism of the adopted fuzzy TOPSIS method, a case company was selected with the objective to rank its eight available projects based on their complex levels. For selecting the most complex project, three groups of decision-makers from the case company were selected to avoid personal bias, to achieve diverse opinions from experts, to validate and to generalize the study outcomes. Members in group 1 were consisted of five project managers, while group 2 consisted of four project planners and group 3 consisted of three project sponsors. The methodological framework followed for selecting a complex project in this study is illustrated in Figure 1.

The procedure of applying the fuzzy TOPSIS method is explained as below:

Step 1: Create a fuzzy decision matrix

A fuzzy decision matrix $(\otimes D)$ is created by obtaining the linguistic variables from the experts or decision-makers. The decision-makers use linguistic words to present preference such as "very low," "low," "medium," "high" and "very high." These linguistic variables are converted to fuzzy sets following fuzzy logic. Table 2 highlights the linguistic variables, notations and corresponding fuzzy set and Figure 2 presents the corresponding triangular membership function. 
JGOSS

14,3

536

Figure 1.

A methodological framework for selecting a complex project

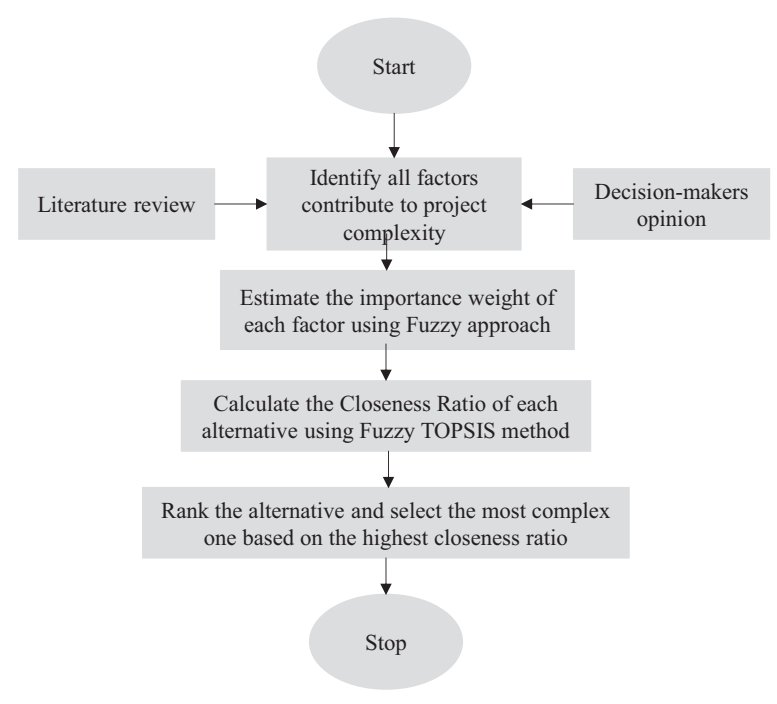

\begin{tabular}{llll} 
Table 2. & Very low & VL & $(1,1,3)$ \\
Linguistic variable, & Low & $\mathrm{L}$ & $(1,3,5)$ \\
notation and & Medium & $\mathrm{M}$ & $(3,5,7)$ \\
corresponding fuzzy & High & $\mathrm{H}$ & $(5,7,9)$ \\
set & Very high & VH & $(7,9,9)$ \\
\hline
\end{tabular}

Figure 2.

Triangular membership function

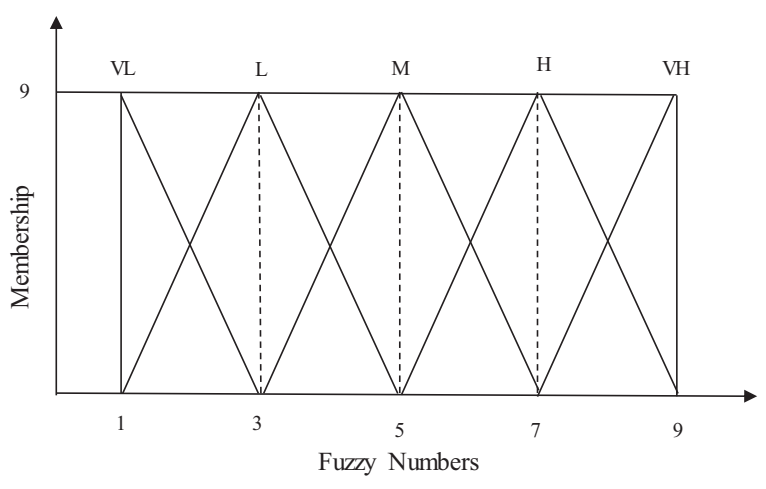

Equation (1) shows the fuzzy decision matrix obtained from expert $l$. In the equation, $x_{i j l}$ represents the linguistic variable received on factor $i(i=1,2 \ldots n)$ for the project $j(j=1,2$, $\ldots \ldots, m)$ from the expert $l(l=1,2, \ldots ., L)$. Each linguistic variable has three values $\left(x_{i j l}=\right.$ $\left.a_{i j l}, b_{i j l}, c_{i j l}\right)$ as shown in Table 2 . Once all experts individually provide their linguistic values 
on the factor relevant to the corresponding project, the aggregate scores of experts are calculated by using the geometric mean, as shown in equation (2). The aggregate fuzzy decision matrix is shown in equation (3).

$$
\begin{gathered}
\otimes D_{l}=\left(\begin{array}{cccc}
x_{111} & x_{21 l} & \cdots & x_{n 1 l} \\
x_{12 l} & x_{221} & \cdots & x_{n 2 l} \\
\cdots & \cdots & \cdots & \cdots \\
x_{1 m l} & x_{2 m l} & \cdots & x_{n m l}
\end{array}\right) \\
\otimes D=\left(\begin{array}{cccc}
y_{11} & y_{21} & \cdots & y_{n 1} \\
y_{12} & y_{22} & \cdots & y_{n 2} \\
\cdots & \cdots & \cdots & \cdots \\
y_{1 m} & y_{2 m} & \cdots & y_{n m}
\end{array}\right) \text { Where, }\left(y_{i j}=a_{i j}, b_{i j}, c_{i j}\right) \\
\prod_{l=1}^{L} x_{i j l}
\end{gathered}
$$

Step 2: Determine the weight vector for the factor

The weighting vector $\left(W=\mathrm{w}_{1}, \mathrm{w}_{2}, \ldots, \mathrm{w}_{\mathrm{n}}\right)$ represents the weight for the given factor assigned by the experts. To assign the weight, the same linguistic variables and values as shown in Table 1 are used. Equation (4) represents the weight matrix obtained from the $l(l=$ $1,2, \ldots . . L)$ experts on factor $i(i=1,2, \ldots, n)$.

$$
\otimes W=\left(\begin{array}{cccc}
w_{11} & w_{21} & \cdots & w_{n 1} \\
w_{12} & w_{22} & \cdots & w_{n 2} \\
\cdots & \cdots & \cdots & \cdots \\
w_{1 L} & w_{2 L} & \cdots & w_{n L}
\end{array}\right)
$$

The weight of factor $i$ is then obtained by taking the average of the experts' linguistics evaluations.

$$
\tilde{w}_{i}=\frac{1}{L}\left(\sum_{l=1}^{L} w_{i l}\right), \quad i=1,2, \ldots, n
$$

\section{Step 3: Normalization of the fuzzy decision matrix}

Normalization of the fuzzy decision matrix is conducted to convert each factor value in between the range of $(0-1)$. For the fuzzy data which is denoted by the triangular fuzzy numbers $\left(a_{i j}, b_{i j}, c_{i j}\right)$, the normalization is done based on equations (6) and (7) according to whether the factor is to be maximized or minimized, respectively.

$$
y_{i j}^{\vee}=\left(\frac{a_{i j}}{c_{i}^{+}}, \frac{b_{i j}}{c_{i}^{+}}, \frac{c_{i j}}{c_{i}^{+}}\right) \quad \text { Where }, c_{i}^{+}=\max _{j}\left(c_{i j}\right), i=1,2, \ldots, n \text { and } j=1,2, \ldots, m
$$

Application of fuzzy TOPSIS framework

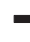

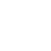


JGOSS

14,3

$$
y_{i j}^{\vee}=\left(\frac{a_{i j}}{c_{i}^{-}}, \frac{b_{i j}}{c_{i}^{-}}, \frac{c_{i j}}{c_{i}^{-}}\right) \quad \text { Where, } c_{i}^{-}=\max _{j}\left(c_{i j}\right), i=1,2, \ldots, n \text { and } j=1,2, \ldots, m
$$

Step 4: Construct weighted normalized fuzzy decision matrix

Weighted matrix is then obtained by multiplying the weight of the factor with the fuzzy normalized decision matrix.

$$
\begin{gathered}
\tilde{K}=\left[\tilde{K}_{i j}\right]_{n x m} \\
\tilde{k}_{i j}=y_{i j}^{\vee} \otimes \tilde{w}_{i}, i=1,2, \ldots, n \text { and } j=1,2, \ldots, m
\end{gathered}
$$

Step 5: Determination of the fuzzy positive ideal solution (FPIS, $A$ *) and fuzzy negative ideal solution (FNIS, A)

The fuzzy positive and negative ideal solutions on the given criterion $i$ represent the maximum and the minimum values, respectively, obtained from the weighted normalized fuzzy decision matrix, among all the alternate projects. The fuzzy positive and negative ideal solutions on the given criterion $i$ are given by equations (10) and (11), respectively.

$$
\begin{aligned}
& A_{i}^{*}=\max _{\forall j \in m}\left(k_{i j}^{\vee}\right), i=1,2, \ldots, n \\
& A_{i}^{-}=\min _{\forall j \in m}\left(k_{i j}^{\vee}\right), i=1,2, \ldots, n
\end{aligned}
$$

Step 6: Calculation of the Euclidian distance of each alternate project from $A_{i}^{*}$ and $A_{i}^{-}$

The Euclidian distance shows how far the alternate project $j$ is from positive and negative ideal solutions. To calculate the distance, at first the distance on individual factor $i$ for the given project $j$ is calculated. Thereafter, the distance on the entire factor is summed up by the following formula.

$$
\begin{aligned}
d_{j}^{*} & =\sum_{i=1}^{n} \sqrt{\frac{1}{3}\left\{\left(a_{i j}^{\vee}-A_{i}^{*}\right)+\left(b_{i j}^{\vee}-A_{i}^{*}\right)+\left(c_{i j}^{\vee}-A_{i}^{*}\right)\right\}}\left(a_{i j}^{\vee}, b_{i j}^{\vee}, c_{i j}^{\vee}\right) \in \tilde{k}_{i j} \text { and } j \\
& =1,2, \ldots, m \\
d_{j}^{-} & =\sum_{i=1}^{n} \sqrt{\frac{1}{3}\left\{\left(a_{i j}^{\vee}-A_{i}^{-}\right)+\left(b_{i j}^{\vee}-A_{i}^{-}\right)+\left(c_{i j}^{\vee}-A_{i}^{-}\right)\right\}}\left(a_{i j}^{\vee}, b_{i j}^{\vee}, c_{i j}^{\vee}\right) \in \tilde{k}_{i j} \text { and } j \\
& =1,2, \ldots, m
\end{aligned}
$$

Step 7: Calculation of the closeness coefficient of each alternate project

The closeness coefficient of each alternate project is calculated by equation (14). 


$$
c c_{i}=\frac{d_{j}^{-}}{d_{j}^{*}+d_{j}^{-}}, j=1,2, \ldots, m
$$

\section{Step 8: Ranking the alternate projects following their closeness coefficients}

At the end, all the studied projects are ranked following their closeness coefficients. Higher the closeness coefficient better will be the ranking and vice versa. The highest closeness coefficient here represents the most complex project in terms of identified factors.

\section{Application of fuzzy TOPSIS framework}

\section{Numerical analysis}

This section uses numerical analysis to demonstrate the selection process of the complex project within a specific case company, engaged in the energy business. This case company is suffering from choosing the most complex projects within its available resources. Keeping such an objective in mind, this study systematically illustrates the procedural steps to choose the most complex project. As a test case, eight projects from the selected company were taken into account.

The case company is a global leader that handles plenty of projects in its everyday business in the energy sector. These projects are usually much complex in nature and the company is struggling to manage their complex projects and prioritize them based on the available resources. It is very critical for the company to manage and share its valuable resources optimally toward the most complex projects. The prioritization of the projects based on their complex level can help the company to work efficiently and to maintain its order of delivery.

This study identified various critical factors responsible for making the project complex. The factors were identified by extensive literature search and after discussions with the personnel, working in the case company's marketing department, technical department and financing department. In total, 11 most critical factors, namely, stakeholders, size, management decisions, technology and tools, resources and capability, cultural diversity, laws and regulations, uncertainty, information exchange, interdependencies and variety were found to be responsible to make the project complex and is presented in Figure 3. There are three layers display in Figure 3. The first layer indicates the object of this study which is to find the complex project, whereas, the second layer highlights all the responsible factors for making a project complex. The third layer highlights all the studied projects, which are to be ranked based on their complexity levels.

The arrows in Figure 3 interpret the relationship among the studied project, identified factors responsible for project complexity and ranking of the studied projects based on the complexity levels. For instance, "stakeholders" is an identified factor responsible to make a project complex, which is also a common factor for all other 11 studied projects and the

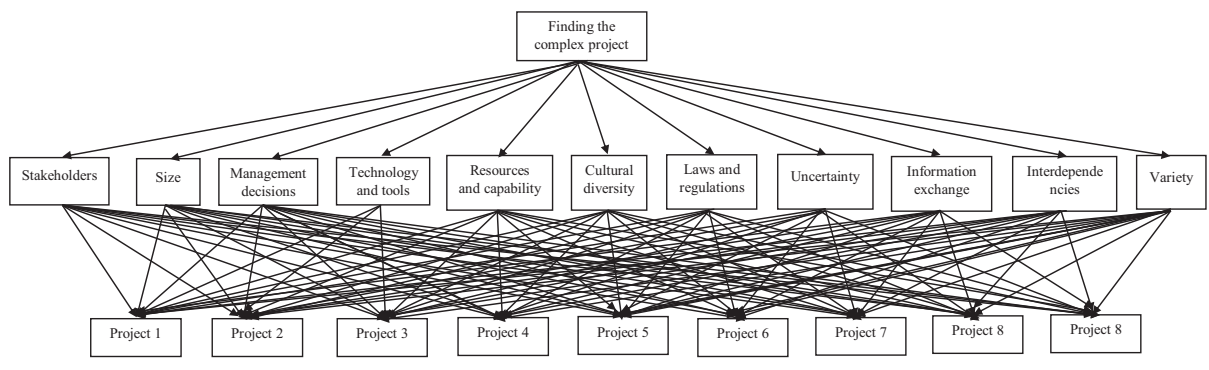

Figure 3.

The hierarchy structure of the factors affecting complex project selection 
JGOSS 14,3

interrelationships are displayed by arrows, etc. All such identified 11 factors can be categorized as economic (resources and capacity, size and uncertainties), technological (technology and tools and information exchange and interdependencies), social (stakeholders, management decisions and cultural diversity) and environmental (laws and regulations and variety). From Figure 3, it is noticed that all the factors responsible to make the project complex is linked to all of the current projects within the case company.

The aims of this case study were to investigate the selected eight projects and rank them according to their complexity levels. To assess each of the eight selected projects, three group decision-makers or experts were chosen from the case company. The following steps were followed for ranking these projects.

According to the Fuzzy TOPSIS method, the opinions as received from three group decision-makers on the factors of project complexity are converted from linguistic values to fuzzy numbers following the numbering system as stated in Table 2 . The linguistic values as presented in Tables 3, 4 and 5 from 3 three different group decision-makers are then converted to fuzzy numbers, which are presented in Tables A1, A2 and A3, respectively, and placed in Appendix. The whole procedure is explained below.

\subsection{Modeling the problem}

\section{Step 1: Creation of the fuzzy decision matrix}

The three group decision-makers were interviewed and requested to give their valuable opinions related to the impacts of the identified factors over the project complexity. Their opinions were categorized as high, average and low impact. The opinions from the three different group decision-makers in the form of linguistic variables are presented in Tables 3 , 4 and 5, respectively.

\section{Step 2: Formulation of the fuzzy decision matrix}

Formulation of the fuzzy decision matrix is done by converting the linguistic terms into triangular fuzzy numbers following the representation in Table 2, which are then replaced into complex decision matrix following equations (4) and (5). The outcomes are presented in Tables A1, A2 and A3, respectively, and placed in the Appendix section (Tables 6 and 7).

Step 3: Normalization of the fuzzy decision matrix

Average fuzzy weightings and ratings and normalization of the fuzzy decision matrix are done following equations (6) and (7) and presented in Tables A1 and A2, respectively.

Step 4: Construction of the weighted normalized fuzzy decision matrix

The construction of the weighted normalized fuzzy decision matrix is done by applying equations (8) and (9) and is presented in Table 8.

Step 5: Calculation of the FPIS and FNIS

Both the FPIS and FNIS are calculated by using equations (10) and (11), respectively and are presented in Tables 9 and 10, respectively.

Step 6: Calculation of the distance from FPIS and FNIS

Following equations (12) and (13), the distance from FPIS and FNIS to each alternate is determined and the outcomes are displayed in Tables 9 and 10, respectively.

Step 7: Calculation of the closeness coefficient

The closeness coefficient of each alternate is determined by using equation (14). The closeness coefficients of eight projects are as shown in Table 11.

Step 8: Ranking based on the closeness coefficient

Based on the closeness coefficients, eight alternate projects are ranked as project $5>$ project $2>$ project $7>$ project $1>$ project $3>$ project $4>$ project $8>\operatorname{project~} 6$ as shown in Table 11. From Table 11, it is noticed that project 5 is the most complex project in the case company. When the closeness coefficients of different projects are very tight, further 


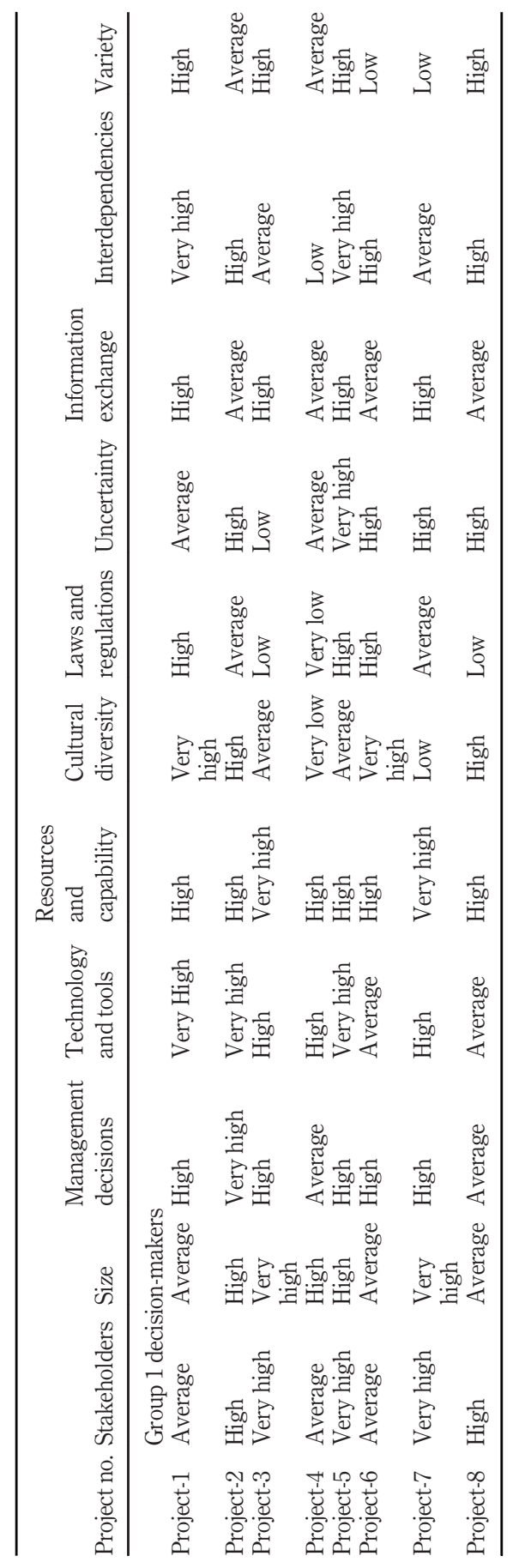

Application of fuzzy TOPSIS framework

Table 3. Opinions of group decision-makers on the factors of project complexity 
JGOSS

14,3

542
Table 4.

Opinions of group decision-makers on the factors of project complexity

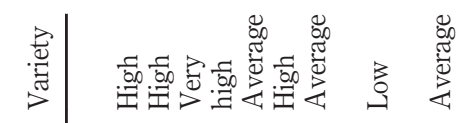

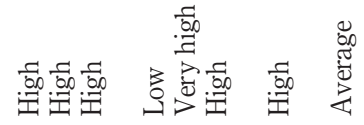

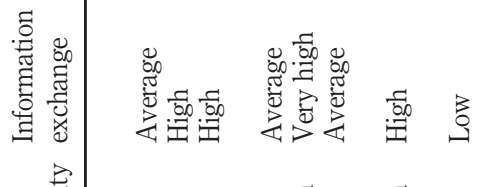

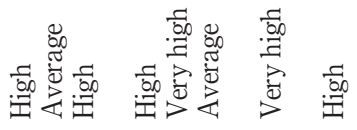

焉

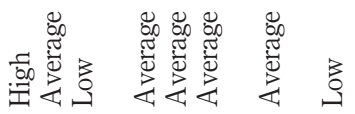

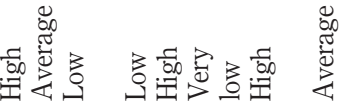

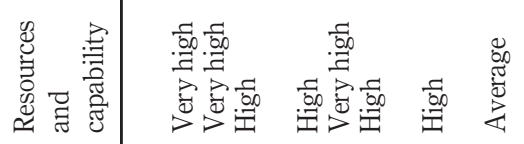

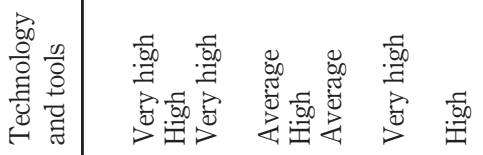

苟

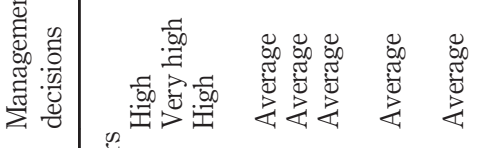
离 \&

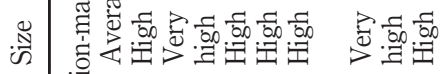

की

융

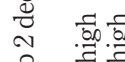

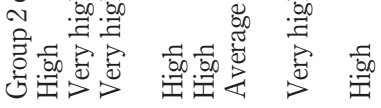

.

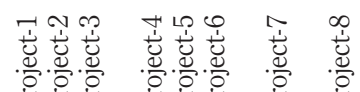




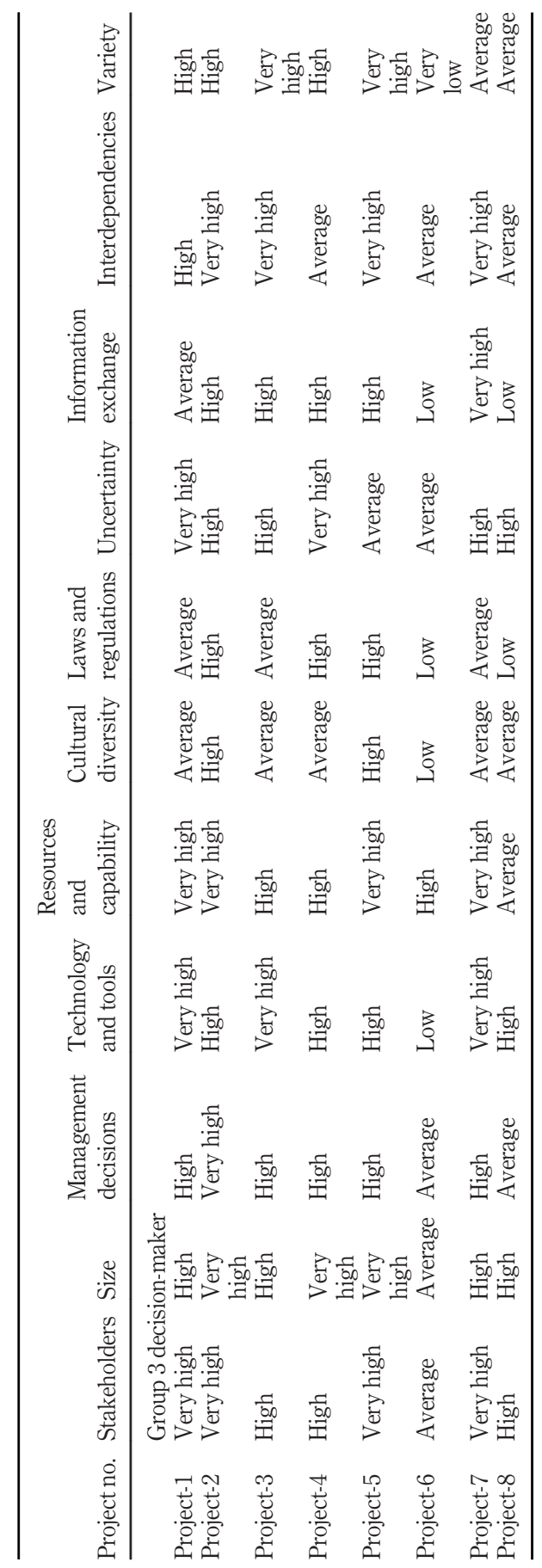

Application of fuzzy TOPSIS framework

Table 5. Opinions of group 3 decision-makers on the factors of project complexity 
JGOSS

14,3

\section{4}

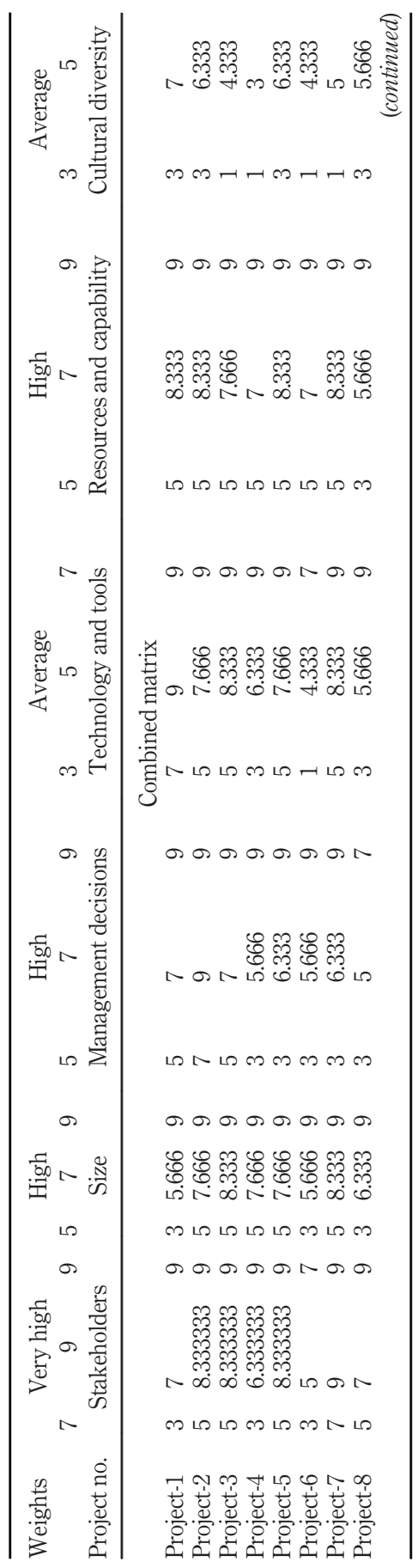

Table 6.

Display of averaged fuzzy weightings and ratings of the eight projects based on the opinions from three groups of decision-makers 


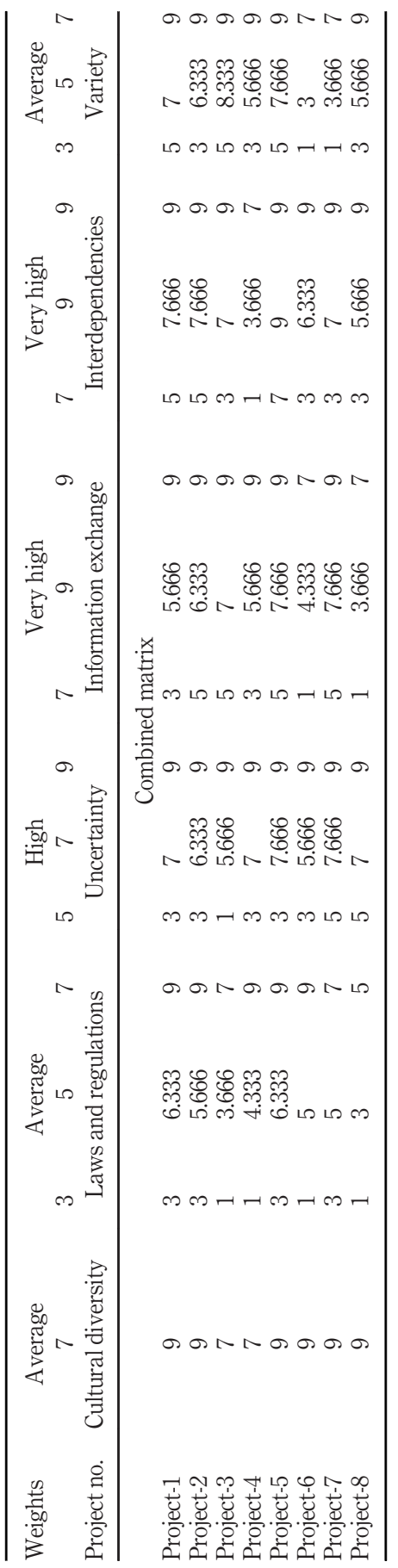

Application of fuzzy TOPSIS framework 
JGOSS

14,3

546
Table 7.

Display of the normalized fuzzy decision matrix

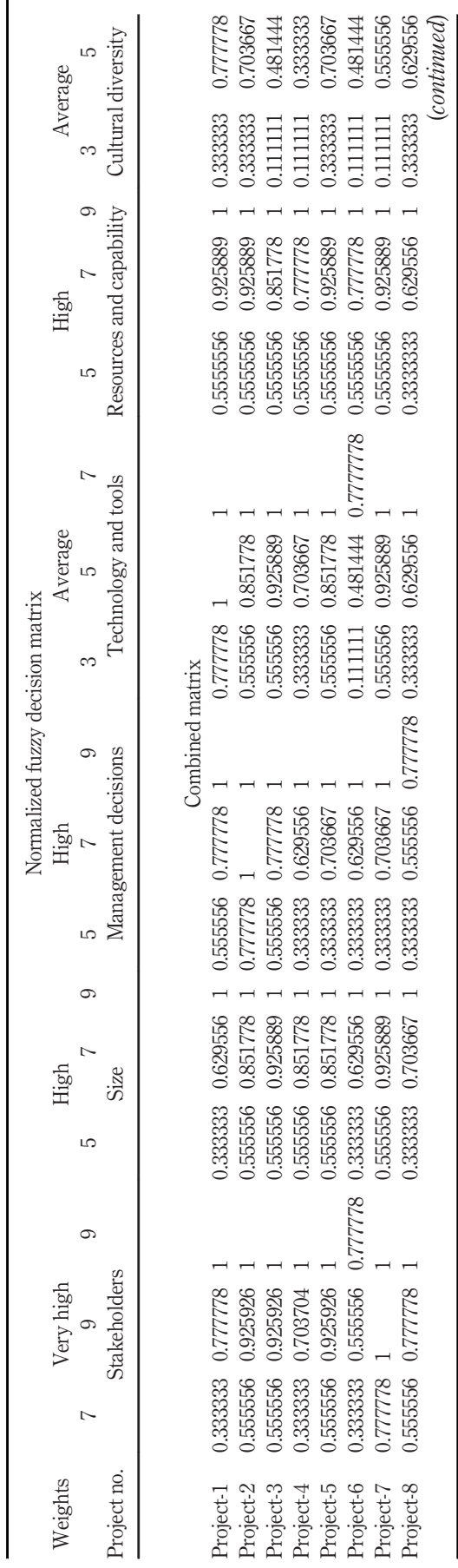




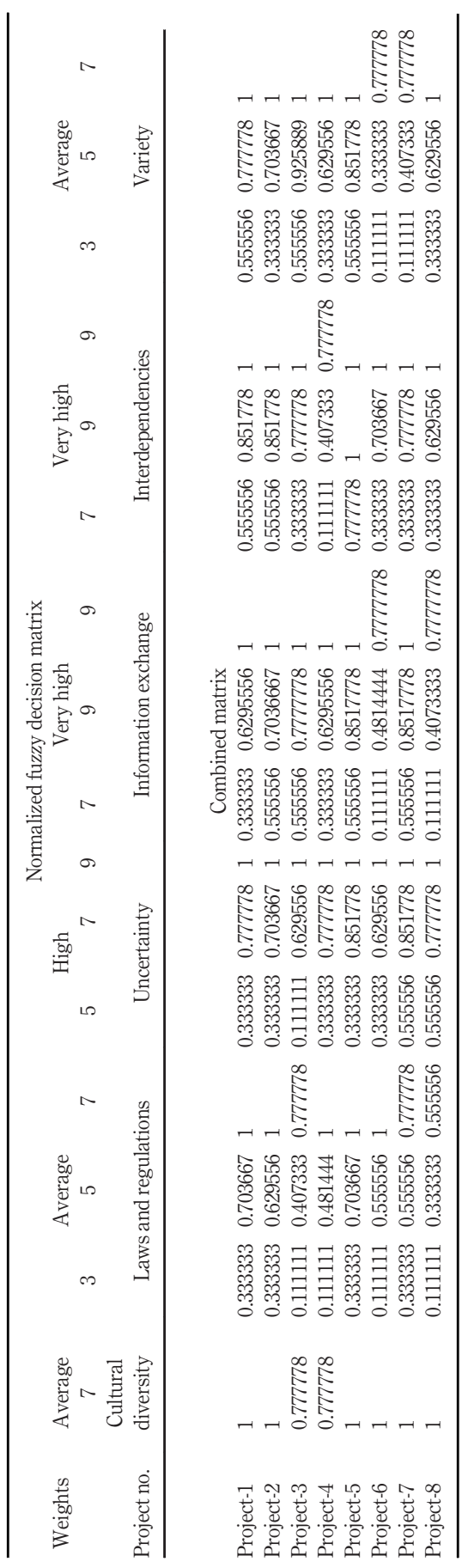

Application of fuzzy TOPSIS framework 
JGOSS

14,3

548

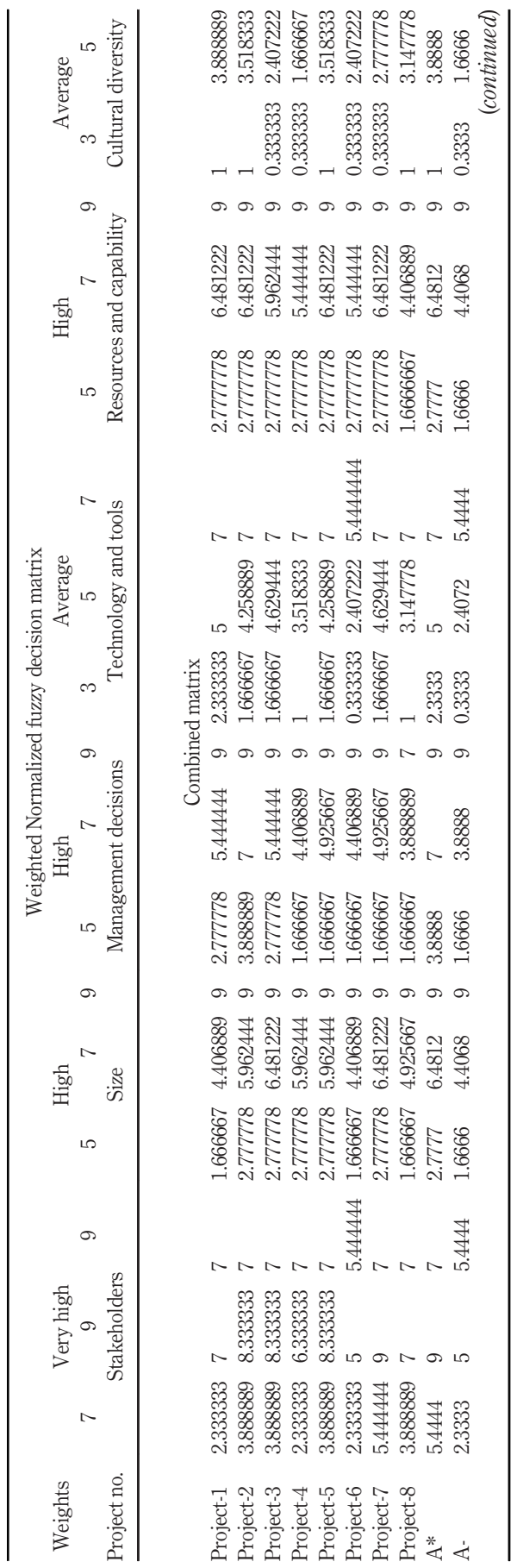

Table 8.

Display of weighted normalized fuzzy decision matrix 


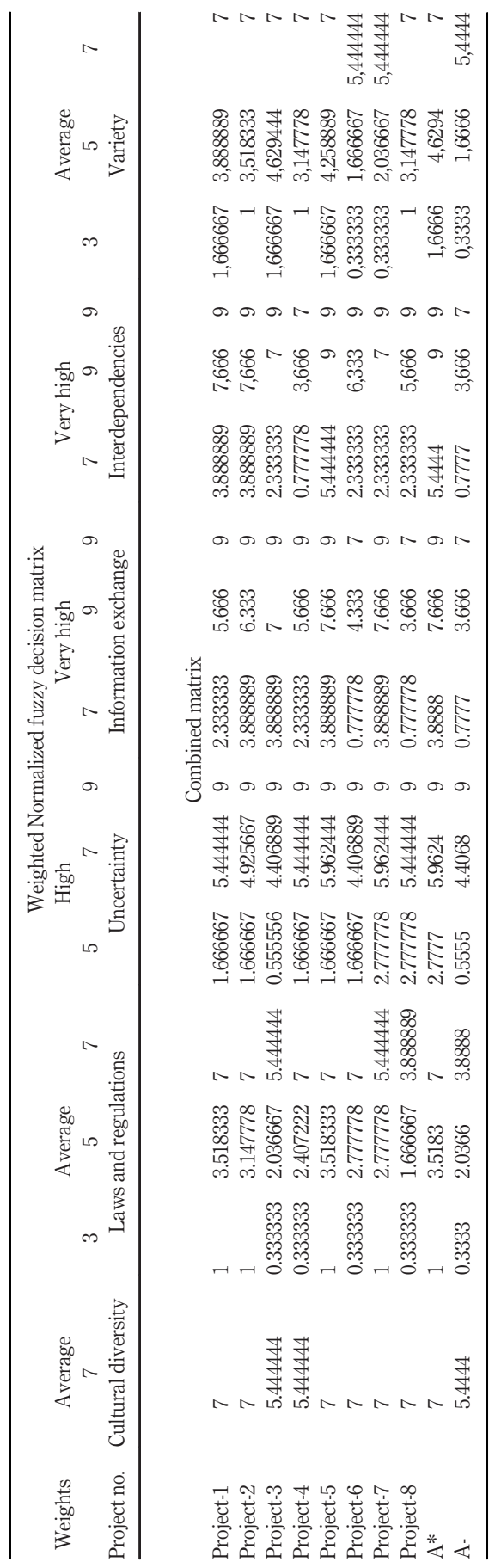

Application of fuzzy TOPSIS framework 
JGOSS

14,3

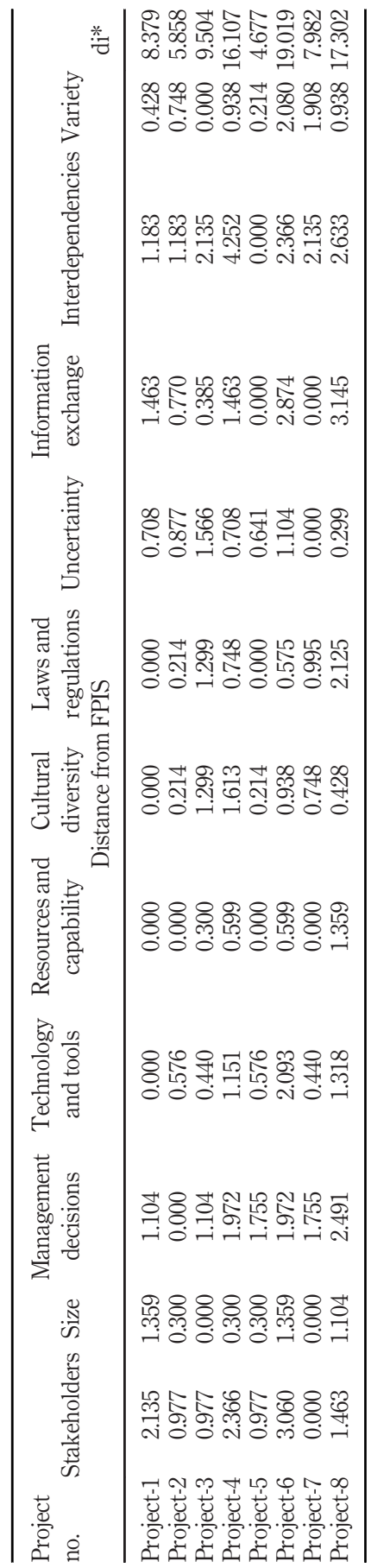

Table 9.

Display of distance measurements (FPIS) of each alternate projects 
JGOSS

14,3

552

Table 11.

Display of opinions

of three groups of

decision-makers from

linguistic values to

fuzzy numbers on

project complexity

factors analysis needs to be conducted to figure out which one is the best choice by considering the case company's previous experience and preference.

\subsection{Sensitivity analysis}

From Section 4.1, it is seen that the experts have given different weights (W) for different factors $(\mathrm{F})$. The change in the weight will have an effect on the project ranking. To check the effect of such change on ranking, sensitivity analysis is conducted. Section 4.1 shows that none of the identified factors deserves lower weight according to the experts. Stakeholder (F1), interdependence (F3) and information exchange (F10) received equal weight i.e. "very high." Similarly, Size (F2), management decision (F5), resource and capability (F8) and uncertainty (F9) received "high" weight. The remaining factors technology and tools (F4), cultural diversity (F6), variety (F7) and laws and regulations (F11) received "average weight." To design the setup for the sensitivity analysis, the factors that received the same weight based on the expert opinion are considered as one group of factors. It means that in the sensitivity analysis three groups of factors were considered, where group 1 consists of factors F1, F3 and F10. Group 2 consists of factors F2, F5, F8 and F9. The remaining factors fall under group 3 . The weight for these groups of factors was varied to see its impact on the ranking of the project. It should be noted that the weights considered in the sensitivity analysis were "very high," "high" and "average" thereby neglecting the level "low." The reason for grouping factors and neglecting low weight is based on the result from section 4.1. Moreover, another reason is due to the fact that if the factors are not grouped and if all the possible weights are considered, then the total set-up for the sensitivity analysis will be equal to (possible weight number of factors), which in this research will result into $4^{\wedge} 11=$ $4,194,304$ combinations. Based on the combination of a group of factors and neglecting "low" weight, altogether $27\left(3^{\wedge} 3\right)$ set-up were generated. Out of the 27 set-ups, it is obvious that three set-ups will lead to the same result i.e. giving equal weight i.e. either "very high" or "high" or "average" to all three groups of factors simultaneously. Therefore, removing the setups, which lead to the same results, altogether 25 setups are considered for the sensitivity analysis as shown in Table 12.

Table 12 shows the closeness coefficient of the projects at different setups. For example, set up number 8 shows that the factor which falls under group 1, group 2 and group 3 are assigned average weight, very high weight and high weight, respectively. At this combination of weight for the criteria, the highest closeness coefficient $(0.8053)$ is achieved by project 5 (P5) and the lowest closeness coefficient (0.3137) is achieved by project 6 (P6). From the table, it is evident that for all 25 set up, P5 achieves the highest closeness coefficient and $\mathrm{P} 6$ achieves the lowest closeness coefficient. Therefore, in terms of ranking of the project, P5 ranks first and P6 ranks last for all the setup. However, in some projects, for

\begin{tabular}{lcc}
\hline $\mathrm{CC}_{\mathrm{i}}$ & Rank & \\
\hline 0.673573 & 4 & Project-1 \\
0.77256 & 2 & Project-2 \\
0.631907 & 5 & Project-3 \\
0.394207 & 6 & Project-4 \\
0.816757 & 1 & Project-5 \\
0.273746 & 8 & Project-6 \\
0.688421 & 3 & Project-7 \\
0.37379 & 7 & Project-8
\end{tabular}




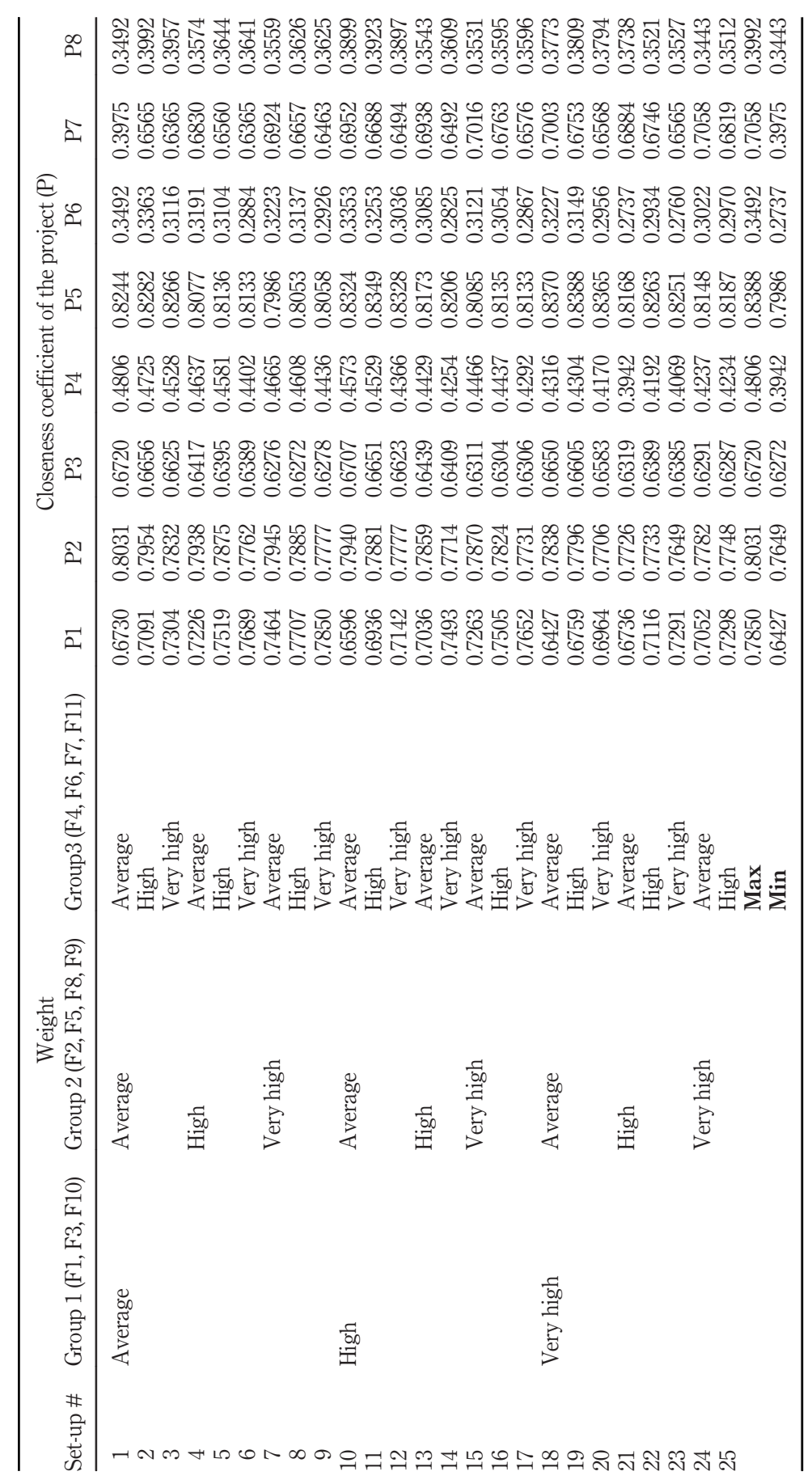

Application of fuzzy TOPSIS framework

553

Table 12. Project closeness coefficient at different weight combination for the group of factors 
JGOSS

14,3

\section{4}

Figure 4 .

Ranking of project and their percentage distribution example, P1 has the second-highest closeness coefficient for setting up 9, while it has the third and fourth highest closeness coefficient for set-up 2 and set-up 1, respectively. Therefore, depending upon the weight combination allocated to the group of factors, the ranking of these projects varies. Irrespective of whether the ranking of the project remains the same at different setups, their closeness coefficient varies with change in the weight combination. The last two rows in the table show the maximum and minimum closeness coefficient achieved by the project under these 25 setups. The closeness coefficient range is the highest for Project 7 (P7), which is equal to 0.3083. Further analysis revealed that the variability in the closeness coefficient, measured in terms of standard deviation, is also highest for P7, which is equal to 0.0585 .

Next, the analysis is carried out to know the percentage distribution of projects in terms of their ranking, the result of which is as shown in Figure 4. The result shows that there is no effect of change in the weight on projects $\mathrm{P} 5, \mathrm{P} 4, \mathrm{P} 8$ and $\mathrm{P} 6$ as for all the set up their ranking is fixed. These projects rank $1^{\text {st }}, 4^{\text {th }}, 7^{\text {th }}$ and $8^{\text {th }}$, respectively. However, for other projects, the effect of weight is evident from the Figure. Project P2 holds the second rank for $96 \%$ of the setup while the remaining $4 \%$ is held by project P1. Similarly, for most of the setup, rank 3 , rank 4 and rank 5 are held by P1 (76\%), P7 (60\%) and P3 (72\%), respectively. From the analysis, it can be seen that even though there is some effect of weight on the project ranking, the effect is mainly over projects $\mathrm{P} 1, \mathrm{P} 3$ and $\mathrm{P} 7$. The ranking of these projects varies between (Rank 3-Rank 5). The effect of weight on only to these limited projects is due to the fact that rather than varying the weight of each factor separately, in the sensitivity analysis, it is varied for the group of factors.

\section{Managerial implications}

Organizational managers are always focused to select their projects, which have the highest possibilities for success. Due to the importance of selecting winning projects for each of the organizations, this issue has been studied a lot. To work with a successful project, it is critical to find out the complex projects, which need special attention to make them successful. During selecting winning projects, it is very important to find out complex projects and categorize them to allocate costly resources efficiently. Researchers studied several ways to identify factors that affect project selection. In general, managers do not have a systematic decision method when there are several projects available for selection to

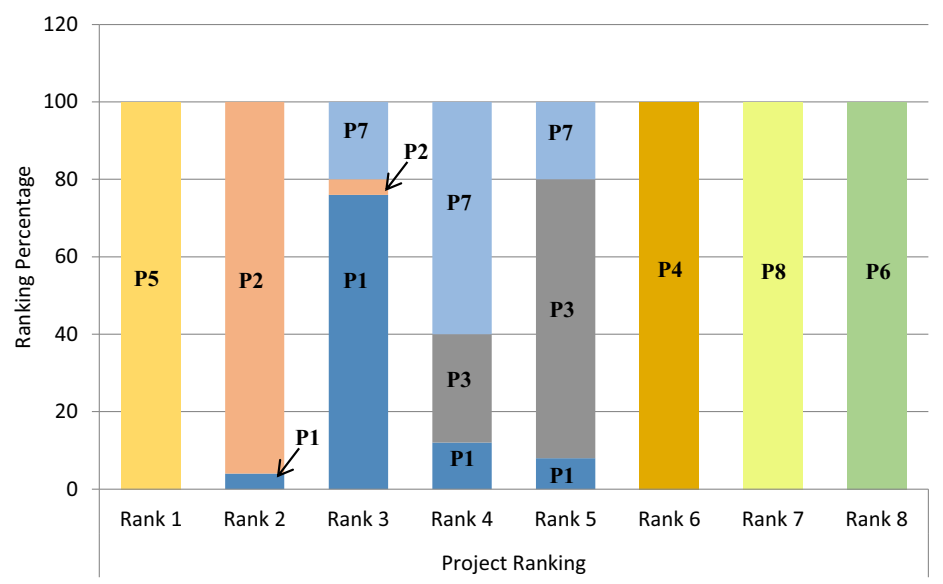


success. It is often a difficult process to select complex projects, where most of the time managers adopt their common sense and experience for the final decision. Managers may often waste money and time if there is no focus to choose the most complex projects from all available projects. It is, therefore, essential to have a proper procedure to help the managers to identify complex projects due to resource scarcity. To overcome ongoing challenges and successfully managing projects, organizations have to recognize the need to know about project management complexity. For many organizations, this has meant to ramp up implementing proper procedural steps to identify and select complex projects out of many fuzzy TOPSIS framework on the same occasion. While anecdotal evidence suggests that selecting, project complexity involves specific challenges and organizations require overcoming them through proper procedural steps. To address this gap in existing knowledge, this study proposed a fuzzybased project selection approach, where relevant factors responsible for project complexities are identified and reviewed. The impacts of such factors on project complexity are assessed through human judgment, which is based on interval judgment and using the linguistic term. All such responses are analyzed through the fuzzy TOPSIS method to offer a triangular membership function to select a complex method. This MCDM process was eventually successfully implemented for solving group decision-making problems.

In this situation, the fuzzy TOPSIS method can be used as an important tool to support managers selecting complex projects following multiple attributes and integrating valuable opinions from experts in the field. Due to the concise and practical nature of the fuzzy TOPSIS method, it is often recommended and suitable to take this tool to accumulate the outcomes from the fuzzy approach. Indeed, the final decision to select a project still depends upon the top management of an organization. The study outcomes open up a methodological approach that helps managers to select their projects based on the complexity levels. Although selecting a complex project is not an easy task but it is usually considered a critical task in organizations. There are limited methods available to select complex projects in organizations and Fuzzy TOPSIS is one of them that might use by the managers to select the complex project. The presented study deliberately explained how complex projects in an organization could be select efficiently. This selection methodology supports top management to maintain their proposed projects with optimum resource allocations and productivity.

\section{Conclusions and future works}

Selection of complex projects has strategic importance for many companies. To select complex projects, at first, the company should identify factors that define a complex project. Thereafter, based on the identified factors, the company may analyze and rank projects based on the level of complexity. This study mainly attempted to answer two important research questions related to a complex project. The first research question is addressed by identifying the factors responsible for project complexity through an extensive review of relevant literature and experts' opinions. The identified factors are needed to be weighted by the experts in the respective domain of project management. In most situations, it is often hard for the experts to give weights on a given set of factors.

The second research question is answered by analyzing the collected factors. For this purpose, the fuzzy TOPSIS method is adopted for ranking all the given sets of project alternates and determines the complex projects chronologically. The proposed approach can support the ranking of complex projects under conditions of incomplete or imprecise information. A numerical analysis is presented demonstrating the working mechanism and effectiveness of the proposed approach. In the analysis, 11 identified factors are considered to select eight projects from a case company engaged in project-based business. All the 
JGOSS 14,3

factors associated with project complexity were sorted out and analyzed based on the linguistic values received from the three individual experts working within the case company. The outcomes from the analysis show that Project 5 is the most complex project within the case company, while Project 6 is the least complex one. From the study results, it can be concluded that the case company requires deploying a more efficient approach for selecting the complex project.

There are various MCDM approaches for optimization such as AHP, TOPSIS, BestWorst DEMATEL, GRA and Vikor. Each of the approaches has its own benefit and limitations. Many kinds of literature have even integrated more than one approach together for the purpose of ranking in various research domains (Piya et al., 2020a, 2020b). The suitability of a specific approach or its integrated form for the ranking of projects may depend on the characteristic of the project. A deeper study is needed in this regard. The research can be extended to compare various MCDM approaches and identify the most suitable approach to rank the complex projects depending upon the characteristic of the project.

This study explores several important dimensions toward managing projects in organizations. It contributes by providing a general guideline on how to explore factors that make a project complex. Not only identifying the factors but this study also validated those factors with experts' opinions who are working in the project management sector. This validation process also enables the authenticity of the factors as collected from an extensive literature survey. In addition, the collected factors were prioritized one over another by using the fuzzy TOPSIS method, which is considered a widely used MCDM process. This prioritization process helps organizational managers to sort the most critical factors that need special attention to avoid project complexity. Moreover, due to the subjective nature of the response from different experts, it was justified to apply the fuzzy model for this study, which also supports more credibility toward the potential outcomes. Furthermore, it is believed that the study results will help project managers to optimize their project selection processes and allocate optimum resources to achieve maximum productivity.

There are several limitations in this study, which are worthy to mention managing the project's complexity efficiently. One of the limitations is that this study identifies 11 drivers of the project's complexity, which are identified by the literature search and can be even more or less in practice. In case of more or fewer drivers of complexity might create even more useful study outcomes. Another limitation is the opinions from the experts, which can be personally biased and effects overall study outcomes. In addition, the study was tested in only one case company, which may not validate the presented approach and generalize the study outcomes for a wider community. In the future, this research study can be extended to examine the aggregation method of attribute weightings and ratings and other types of membership functions, for example, trapezoidal or exponential. In addition, a software package can be designed to automate the calculation process and make it more efficient and authentic.

\section{References}

Ahmadi, S., Khanagha, S., Berchicci, L. and Jansen, J.J.P. (2017), “Are managers motivated to explore in the face of a new technological change? The role of regulatory focus, fit, and complexity of decision-making", Journal of Management Studies, Vol. 54 No. 2, pp. 209-237.

Akadiri, P.O., Olomolaiye, P.O. and Chinyio, E.A. (2013), "Multicriteria evaluation model for the selection of sustainable materials for building projects", Automation in Construction, Vol. 30, pp. 113-125. 
Akhavan, P., Philsoophian, M. and Karimi, M.H. (2019), "Selection and prioritization of knowledge management strategies as proportionate with organizations' level of maturity using fuzzy TOPSIS approach, case study: a research organization", VINE Journal of Information and Knowledge Management Systems, Vol. 49 No. 3, pp. 397-419.

Application of fuzzy TOPSIS framework

Al Zaabi, H. and Bashir, H. (2020), "Modeling and analyzing project interdependencies in project portfolios using an integrated social network analysis-fuzzy TOPSIS MICMAC approach", International Journal of System Assurance Engineering and Management, Vol. 11 No. 6, pp. 1083-1106.

Alkhatib, S.F. (2017), "Strategic logistics outsourcing: upstream-downstream supply chain comparison", Journal of Global Operations and Strategic Sourcing, Vol. 10 No. 3, pp. 309-333.

Arditi, D., Nayak, S. and Damci, A. (2017), "Effect of organizational culture on delay in construction", International Journal of Project Management, Vol. 35 No. 2, pp. 136-147.

Bakhshi, J., Ireland, V. and Gorod, A. (2016), "Clarifying the project complexity construct: past, present and future", International Journal of Project Management, Vol. 34 No. 7, pp. 1199-1213.

Beatriz Forés, B. and César Camisón, C. (2016), "Does incremental and radical innovation performance depend on different types of knowledge accumulation capabilities and organizational size?", Journal of Business Research, Vol. 69 No. 2, pp. 831-848.

Beldek, T., Konyalığlu, A.K. and Camgöz-Akdağ, H. (2020), “A fuzzy MCDM approach for project selection criteria prioritization in a Big-Four company: Evidences from Turkey consultancy sector", in Kahraman C., Cebi S., Cevik Onar S., Oztaysi B., Tolga A. and Sari I. (Eds), Intelligent and Fuzzy Techniques in Big Data Analytics and Decision Making. INFUS 2019. Advances in Intelligent Systems and Computing, Vol. 1029, Springer, Cham, 10.1007/978-3-030-23756-1_95.

Beste, C., T. Welo, T. and Olsson, N. (2020), "Influence of innovation, complexity and newness on success in new product development projects: a survey in Norwegian manufacturing industry", Proceedings of the Design Society: DESIGN Conference, Vol. 1, pp. 511-520.

Bjorvatn, T. and Wald, A. (2018), "Project complexity and team-level absorptive capacity as drivers of project management performance", International Journal of Project Management, Vol. 36 No. 6 , pp. 876-888.

Bosch-Rekveldt, M., Jongkind, Y., Mooi, H., Bakker, H. and Verbraeck, A. (2011), "Grasping project complexity in large engineering projects: the TOE (technical, organizational and environmental) framework", International Journal of Project Management, Vol. 29 No. 6, pp. 728-739.

Büyüközkan, G., Güleryüz, G. and Karpak, B. (2017), “A new combined IF-DEMATEL and IF-ANP approach for CRM partner evaluation”, International Journal of Production Economics, Vol. 191, pp. 194-206.

Büyüközkan, G. and Göçer, F. (2017), "Application of a new combined intuitionistic fuzzy MCDM approach based on axiomatic design methodology for the supplier selection problem", Applied Soft Computing, Vol. 52, pp. 1222-1238.

Chen, C.T. (2000), "Extensions of the TOPSIS for group decision-making under fuzzy environment", Fuzzy Sets and Systems, Vol. 114 No. 1, pp. 1-9.

Chen, C.T. and Cheng, H.L. (2009), "A comprehensive model for selecting information system project under fuzzy environment", International Journal of Project Management, Vol. 27 No. 4, pp. 389-399.

Chowdhury, M.M.H., Paul, S.K., Sianaki, O.A. and Quaddus, M.A. (2020), "Dynamic sustainability requirements of stakeholders and the supply portfolio", Journal of Cleaner Production, Vol. 255, p. 10.

Chukwumaobi, O., Akinlabi, E.T. and Njoku, H.O. (2020), "Selection of phase change material for improved performance of trombe wall systems using the entropy weight and TOPSIS methodology", Energy and Buildings, Vol. 217, p. 109967.

Contractor, R. (2018), Democratized Living: An Examination of How Digital Tools in the Use of a Transitional Shelter Can Affect Building Methods. (Unpublished Document Submitted in Partial 
JGOSS 14,3
Fulfiment of the Requirements for the Degree of Master of Architecture (Professional)), Unitec Institute of Technology, Auckland, New Zealand.

Cui, L., Chan, H.K., Zhou, Y., Dai, J. and Lim, J.J. (2019), "Exploring critical factors of green business failure based on grey-decision making trial and evaluation laboratory (DEMATEL)", Journal of Business Research, Vol. 98, pp. 450-461.

Damayanti, R.W., Hartono, B. and Wijaya, A.R. (2019), "Megaproject complexity: conceptual study from complexity theory", IEEE 6th International Conference on Engineering Technologies and Applied Sciences (ICETAS), Kuala Lumpur, Malaysia, 2019, pp. 1-6.

Dandage, R., Mantha, S. and Rane, S. (2018), "Ranking the risk categories in international projects using the TOPSIS method", International Journal of Managing Projects in Business, Vol. 11 No. 2, pp. 317-331.

Dandage, R.V., Rane, S.B. and Mantha, S.S. (2021), "Modelling human resource dimension of international project risk management", Journal of Global Operations and Strategic Sourcing, Vol. ahead-of-print No. ahead-of-print.

Darcy, C., Hill, J., McCabe, T.J. and McGovern, P. (2014), "A consideration of organisational sustainability in the SME context: a resource-based view and composite model", European Journal of Training and Development, Vol. 38 No. 5, pp. 398-414.

Davoudabadi, R., Mousavi, S.M., Šaparauskas, J. and Gitinavard, H. (2019), "Solving construction project selection problem by a new uncertain weighting and ranking based on compromise solution with linear assignment approach", Journal of Civil Engineering and Management, Vol. 25 No. 3, pp. 241-251.

De Brucker, K., Macharis, C. and Verbeke, A. (2013), "Multi-criteria analysis and the resolution of sustainable development dilemmas: a stakeholder management approach", European Journal of Operational Research, Vol. 224 No. 1, pp. 122-131.

Dobrovolskiene, N. and Tamosiuniene, R. (2016), "Sustainability-Oriented financial resource allocation in a project portfolio through multi-criteria decision making”, Sustainability, Vol. 8 No. 5, p. 485.

Du, Y., Gao, C., Hu, Y., Mahadevan, S. and Deng, Y. (2014), "A new method of identifying influential nodes in complex networks based on TOPSIS", Physica A: Statistical Mechanics and Its Applications, Vol. 399, pp. 57-69.

Duzce, S.A. (2015), "A new ranking method for Trapezial fuzzy numbers and its application to fuzzy risk analysis”, Journal of Intelligent and Fuzzy Systems, Vol. 28 No. 3, pp. 1411-1419.

Engström, G., Sollander, K., Hilletofth, P. and Eriksson, D. (2018), "Reshoring drivers and barriers in the swedish manufacturing industry", Journal of Global Operations and Strategic Sourcing, Vol. 11 No. 2, pp. 174-201.

Erdin, C. and Akbaş, H.E. (2019), "A comparative analysis of fuzzy TOPSIS and geographic information systems (GIS) for the location selection of shopping malls: a case study from Turkey”, Sustainability, Vol. 11 No. 14, p. 3837.

Fei, L., Hu, Y., Xiao, F., Chen, L. and Deng, Y. (2016), “A modified topsis method based on numbers and its applications in human resources selection", Mathematical Problems in Engineering, Vol. 2016.

Floricel, S., Michela, J.L. and Piperca, S. (2016), “Complexity, uncertainty-reduction strategies, and project performance”, International Journal of Project Management, Vol. 34 No. 7, pp. 1360-1383.

Floyd, M.K., Barker, K., Rocco, C.M. and Whitman, M.G. (2017), “A multi-criteria decision analysis technique for stochastic task criticality in project management", Engineering Management Journal, Vol. 29 No. 3, pp. 165-178.

Frini, A. and BenAmor, S. (2015), "A TOPSIS multi-criteria multi-period approach for selecting projects in sustainable development context”, 2015 International Conference on Industrial Engineering and Operations Management (IEOM), 3-5 March 2015, Dubai, United Arab Emirates. 
Ganesan, K. and Veeramani, P. (2006), "Fuzzy linear programs with trapezoidal fuzzy numbers", Annals of Operations Research, Vol. 143 No. 1, pp. 305-315.

Ghapanchi, A.H., Tavana, M., Khakbaz, M.H. and Low, G. (2012), "A methodology for selecting portfolios of projects with interactions and under uncertainty”, International Journal of Project Management, Vol. 30 No. 7, pp. 791-803.

Gupta, S., Soni, U. and Kumar, G. (2019), "Green supplier selection using multi-criterion decision making under fuzzy environment: a case study in automotive industry", Computers and Industrial Engineering, Vol. 136, pp. 663-680.

Hamdan, S., Hamdan, A., Bingamil, A., Al-Zarooni, H., Bashir, H. and Alsyouf, I. (2019), "Investigating delay factors in electrical installation projects using fuzzy TOPSIS”, 2019 8th International Conference on Modeling Simulation and Applied Optimization (ICMSAO), 15-17 April 2019, Manama, Bahrain.

Han, B., Zhang, X.X. and Yi, Y. (2019), "Multi-criteria project selection using fuzzy preference relations based AHP and TOPSIS”, 2019 Chinese Control and Decision Conference (CCDC), 3-5 June, Nanchang, China.

Haque, M. and Islam, R. (2018), "Impact of supply chain collaboration and knowledge sharing on organizational outcomes in pharmaceutical industry of Bangladesh", Journal of Global Operations and Strategic Sourcing, Vol. 11 No. 3, pp. 301-320.

Hatch, M.J. and Cunliffe, A.L. (2012), Organization Theory: modern, Symbolic and Postmodern Perspectives, Oxford University Press.

He, Q., Luo, L., Hu, Y. and Chan, A.P.C. (2015), "Measuring the complexity of mega construction projects in China-a fuzzy analytic network process analysis”, International Journal of Project Management, Vol. 33 No. 3, pp. 549-563.

Jafarzadeh, H., Akbari, P. and BabakAbedin, B. (2018), “A methodology for project portfolio selection under criteria prioritisation, uncertainty and projects interdependency - combination of fuzzy QFD and DEA", Expert Systems with Applications, Vol. 110, pp. 237-249.

Jaukovic, J.K., Jocic, G., Karabasevic, D., Popovic, G., Stanujkic, D., Zavadskas, E.K. and Thanh Nguyen, T.P. (2020), "A novel integrated PIPRECIA-Interval-Valued triangular fuzzy ARAS model: E-Learning course selection”, Symmetry, Vol. 12 No. 6, pp. 9-28.

Jesse Kivilä, J., Miia Martinsuo, M. and Lauri Vuorinen, L. (2017), "Sustainable project management through project control in infrastructure projects", International Journal of Project Management, Vol. 35 No. 6, pp. 1167-1183.

Kahraman, C., Onar, S.C. and Oztaysi, B. (2015), "Fuzzy multicriteria decision-making: a literature review”, International Journal of Computational Intelligence Systems, Vol. 8 No. 4, pp. 637-666.

Kahraman, C., Kahraman, C., Yasin Ateş, N., Çevik, S., Gülbay, M. and Erdoğan, S.A. (2007), "Hierarchical fuzzy TOPSIS model for selection among logistics information technologies", Journal of Enterprise Information Management, Vol. 20 No. 2, pp. 143-168.

Kannan, G., Pokharel, S. and Kumar, P.S. (2009), "A hybrid approach using ISM and fuzzy TOPSIS for the selection of reverse logistics provider”, Resources, Conservation and Recycling, Vol. 54 No. 1, pp. 28-36.

Kannan, D., Khodaverdi, R., Olfat, L., Jafarian, A. and Diabat, A. (2013), "Integrated fuzzy multi criteria decision making method and multi-objective programming approach for supplier selection and order allocation in a green supply chain”, Journal of Cleaner Production, Vol. 47, pp. 355-367.

Kermanshachia, S., Daoa, B., Shaneb, J. and Andersona, S. (2016), "Project complexity indicators and management Strategies- A Delphi study”, Procedia Engineering, Vol. 145, pp. 587-594.

Kermanshachi, S., Dao, B., Rouhanizadeh, B., Shane, J. and Anderson, S. (2020), "Development of the project complexity assessment and management framework for heavy industrial projects", International Journal of Construction Education and Research, Vol. 16 No. 1, pp. 24-42.
Application of fuzzy TOPSIS framework 
JGOSS 14,3
Kermanshachi, S., Dao, B., Shane, J. and Anderson, S. (2016), "An empirical study into identifying project complexity management strategies”, Procedia Engineering, Vol. 145, pp. 603-610.

Kerzner, H. and Thamhain, H.J. (1986), Project Management Operating Guidelines: Directives, Procedures and Forms, Van Nostand Reinhold, New York, NY.

Khadem, M.M.R.K., Piya, S. and Shamsuzzoha, A. (2018), "Quantitative risk management in gas injection project: a case study from Oman oil and gas industry", Journal of Industrial Engineering International, Vol. 14 No. 3, pp. 637-654.

Kharat, M.G., Murthy, S., Kamble, S.J., Raut, R.D., Kamble, S.S. and Kharat, M.G. (2019), "Fuzzy multicriteria decision analysis for environmentally conscious solid waste treatment and disposal technology selection”, Technology in Society, Vol. 57, pp. 20-29.

Koohathongsumrit, N. and Meethom, W. (2021), "An integrated approach of fuzzy risk assessment model and data envelopment analysis for route selection in multimodal transportation networks", Expert Systems with Applications, Vol. 171, p. 114342.

Kumar, R., Chandrawat, R.K., Sarkar, B., Joshi, V. and Majumder, A. (2021), “An advanced optimization technique for smart production using $\alpha$-cut based quadrilateral fuzzy number", International Journal of Fuzzy Systems, Vol. 23 No. 1, pp. 107-127.

Kumar, A., Kashyap, K., Malhotra, H., Rawat, K., Kumar, G. and Soni, U. (2019), "Preferential selection of locations for installing CCTV using fuzzy TOPSIS approach: a case study for North Delhi”, 2019 IEEE Twelfth International Conference on Contemporary Computing (IC3), August 08-10, Noida, India, pp. 1-7.

Lam, W.S., Lam, W.H., Jaaman, S.H. and Liew, K.F. (2021), "Performance evaluation of construction companies using integrated entropy-fuzzy VIKOR model”, Entropy, Vol. 23 No. 3, p. 320.

Li, Y., Lu, Y., Kwak, Y.H. and Dong, S. (2015), "Developing a city-level multi-project management information system for chinese urbanization”, International Journal of Project Management, Vol. 33 No. 3, pp. 510-527.

Liang, R., Zhang, J., Wu, C. and Sheng, Z. (2019), "Joint-venture contractor selection using competitive and collaborative criteria with uncertainty", Journal of Construction Engineering and Management, Vol. 145 No. 2, February.

Lu, Y., Luo, L., Wang, H., Le, Y. and Shi, Q. (2015), "Measurement model of project complexity for largescale projects from task and organization perspective", International Journal of Project Management, Vol. 33 No. 3, pp. 610-622.

Ma, J., Harstvedt, J.D., Jaradat, R. and Smith, B. (2020), "Sustainability driven multi-criteria project portfolio selection under uncertain decision-making environment", Computers and Industrial Engineering, Vol. 140 No. February, p. 106236.

Mahmoud-Jouini, S.B., Midler, C. and Silberzahn, P. (2016), “Contributions of design thinking to project management in an innovation context", Project Management Journal, Vol. 47 No. 2, pp. 144-156.

Mishra, D. and Mahanty, B. (2019), "Study of maintenance project manpower dynamics in Indian software outsourcing industry", Journal of Global Operations and Strategic Sourcing, Vol. 12 No. 1, pp. 62-81.

Morris, P.W.G. (2013), Reconstructing Project Management, Chichester, West Sussex; Wiley-Blackwell.

Nguyen, L.D., Le-Hoai, L., Tran, D.Q., Dang, C.N. and Nguyen, C.V. (2019), "Effect of project complexity on cost and schedule performance in transportation projects", Construction Management and Economics, Vol. 37 No. 7, pp. 384-399.

Noktehdan, M., Zare, M.R., Adafin, J., Wilkinson, S. and Shahbazpour, M. (2020), “Application of fuzzy analytic hierarchy process (AHP) for ranking and selection of innovation in infrastructure project management", in Roggema R. and Roggema A. (Eds), Smart and Sustainable Cities and Buildings, Springer, Cham.

Park, K., Kremer, G.E.K. and Ma, J. (2018), “A regional information-based multi-attribute and multiobjective decision-making approach for sustainable supplier selection and order allocation", Journal of Cleaner Production, Vol. 187, pp. 590-604. 
Patil, A., Shardeo, V., Dwivedi, A. and Madaan, J. (2020), "An integrated approach to model the blockchain implementation barriers in humanitarian supply chain”, Journal of Global Operations and Strategic Sourcing, Vol. 14 No. 1, pp. 81-103.

Pedrycz, W. (1994), “Why triangular membership functions?”, Fuzzy Sets and Systems, Vol. 64 No. 1, pp. 21-30.

Application of fuzzy TOPSIS framework

Piya, S., Shamsuzzoha, A. and Khadem, M. (2019), "An approach for analysing supply chain complexity drivers through interpretive structural modelling", International Journal of Logistics Research and Applications, pp. 1-26.

Piya, S., Shamsuzzoha, A., Khadem, M. and AlKindi, M. (2020a), "Integrated analytical hierarchy process and grey relational analysis approach to measure supply chain complexity, benchmarking: an international journal, Publsihed online on 8 December 2020", doi: 10.1108/BIJ03-2020-0108.

Piya, S., Shamsuzzoha, A., Khadem, M. and Al-Hinai, N. (2020b), "Identification of critical factors and their inter-relationships to design agile supply chain: special focus to oil and gas industries", Global Journal of Flexible Systems Management, Vol. 21 No. 3, pp. 263-281.

Poveda-Bautista, R., Diego-Mas, J-A. and Leon-Medina, D. (2018). "Measuring the project management complexity: the case of information technology projects", Complexity, 2018, p. 19.

Pramanik, D., Mondal, S.C. and Haldar, A. (2020). "A framework for managing uncertainty in information system project selection: an intelligent fuzzy approach", International Journal of Management Science and Engineering Management, Vol. 15 No. 1.

Prascevic, N. and Prascevic, Z. (2017), "Application of fuzzy AHP for ranking and selection of alternatives in construction project management", Journal of Civil Engineering and Management, Vol. 23 No. 8, pp. 1123-1135.

Project Management Institute (2013), A Guide to the Project Management Body of Knowledge (PMBOK® Guide), Fifth Edition, New town Square, PA, USA: Project Management Institute, p. 589, ISBN 978-1935589679.

Rajak, M. and Shaw, K. (2019), "Evaluation and selection of mobile health (mHealth) applications using AHP and fuzzy TOPSIS", Technology in Society, Vol. 59, p. 101186.

Roghanian, E. and Bazleh, A. (2011), “An approach in BOT project selection based on fuzzy QFD and TOPSIS with consideration of risk", Proceedings of the 3rd Conference on Thermal Power Plants (CTPP), Tehran, Iran.

Romasheva, N. and Ilinova, A. (2019), "CCS projects: How regulatory framework influences their deployment”, Resources, Vol. 8 No. 4, p. 181, doi: 10.3390/resources8040181.

Rumeser, D. and Emsley, M. (2019), "Can serious games improve project management decision making under complexity?", Project Management Journal, Vol. 50 No. 1.

Sadi-Nezhad, S. (2017), “A state-of-art survey on project selection using MCDM techniques", Journal of Project Management, Vol. 2 No. 1, pp. 1-10.

Safapour, E., Kermanshachi, S. and Ramaji, I. (2018), "Entity-based investigation of project complexity impact on size and frequency of construction phase change orders", Construction Research Congress, pp. 681-691.

Sahin, B. and Yip, T.L. (2017), "Shipping technology selection for dynamic capability based on improved Gaussian fuzzy AHP model”, Ocean Engineering, Vol. 136, pp. 233-242.

San Cristóbal, J.R. (2017), “Complexity in Project Management”, Procedia Computer Science, Vol. 121, pp. $762-766$.

Schultz, C., Graw, J., Salomo, S. and Kock, A. (2019), "How project management and top management involvement affect the innovativeness of professional service organizations - an empirical study on hospitals", Project Management Journal, Vol. 50 No. 4.

Sener, U., Gokalp, E. and Eren, P.E. (2018), "ClouDSS: a decision support system for cloud service selection", Proceedings of International Conference on the Economics of Grids, Clouds, Systems, and Services, Biarritz, France, 19-21 September 2017, Springer: Cham, Germany, pp. 249-261. 
JGOSS 14,3

Sharma, M.G. and Naude, M.J. (2021), "Interdependence analysis of supplier relationship challenges in the South African automotive industry", Journal of Global Operations and Strategic Sourcing, Vol. ahead-of-print No. ahead-of-print.

Shaygan, A. and Testik, O.M. (2019), "A fuzzy AHP-based methodology for project prioritization and selection”, Soft Computing, Vol. 23 No. 4, pp. 1309-1319.

Singh, R.K., Gunasekaran, A. and Kumar, P. (2018), "Third party logistics (3PL) selection for cold chain management: a fuzzy AHP and fuzzy TOPSIS approach", Annals of Operations Research, Vol. 267 No. 1-2, pp. 531-553.

Stretton, A. (2017), "Some representations of how projects and/or their management relate to a variety of contexts", PM World Journal, Vol. V No. VI.

Stretton, A. (2019), "Representations of a variety of contexts which impact on the management of projects", PM World Journal, No. VIII (V, June).

Sun, L.Y., Miao, C.L. and Yang, L. (2017), "Ecological-economic efficiency evaluation of green technology innovation in strategic emerging industries based on entropy weighted TOPSIS method", Ecological Indicators, Vol. 73, pp. 554-558.

Tafi, M.H.A. (2013), "Risks factors associated with offshore IT outsourcing", Industrial Management and Data Systems, Vol. 105 No. 5, pp. 549-560.

Tan, Y., Shen, L., Langston, C. and Liu, Y. (2010), "Construction project selection using fuzzy TOPSIS approach", Journal of Modelling in Management, Vol. 5 No. 3, pp. 302-315.

Taylan, O., Bafail, A.O., Abdulaal, R.M.S. and Kabli, M.R. (2014), "Construction projects selection and risk assessment by fuzzy AHP and fuzzy TOPSIS methodologies", Applied Soft Computing Journal, Vol. 17.

Trinh, M.T. and Feng, Y. (2020), "Impact of project complexity on construction safety performance: moderating role of resilient safety culture", Journal of Construction Engineering and Management, Vol. 146 No. 2.

Tzeng, G.H. and Huang, J.J. (2011), Multiple Attribute Decision Making: methods and Applications, CRC press.

Venkatesh, V.G., Zhang, A., Deakins, E., Luthra, S. and Mangla, S. (2019), “A fuzzy AHP-TOPSIS approach to supply partner selection in continuous aid humanitarian supply chains", Annals of Operations Research, Vol. 283 No. 1-2, pp. 1517-1550.

Vidal, L.A., Marle, F. and Bocquet, J.C. (2011a), "Measuring project complexity using the analytic hierarchy process", International Journal of Project Management, Vol. 29 No. 6, pp. 718-727.

Vidal, L.A., Marle, F. and Bocquet, J.C. (2011b), "BocquetUsing a delphi process and the analytic hierarchy process (AHP) to evaluate the complexity of projects", Expert Systems with Applications, Vol. 38 No. 5, pp. 5388-5405.

Vinodh, S. and Devadasan, S.R. (2011), "Twenty criteria based agility assessment using fuzzy logic approach", The International Journal of Advanced Manufacturing Technology, Vol. 54 Nos No. 9/12, pp. 1219-1231.

Wang, Q., Hauge, J.B. and Meijer, S. (2020), "Adopting an actor analysis framework to a complex technology innovation project: a case study of an electric road system”, Sustainability, Vol. 12 No. 1, p. 313 .

Westfall, A. (2020), "Information technology project failure caused by inadequate project scoping: an exploratory qualitative inquiry on inadequate project scopes", $\mathrm{PhD}$ thesis, Capella University, MN.

White, L., Currie, G. and Lockett, A. (2016), "Pluralized leadership in complex organizations: exploring the cross network effects between formal and informal leadership relations", The Leadership Quarterly, Vol. 27 No. 2, pp. 280-297. 
Woschke, T., Haase, H. and Kratzer, J. (2017), "Resource scarcity in SMEs: effects on incremental and radical innovations", Management Research Review, Vol. 40 No. 2, pp. 195-217.

Yalcin, A.S., Kilic, H.S. and Guler, E. (2019), "Research and development project selection via IFDEMATEL and IF-TOPSIS", Intelligent and Fuzzy Techniques in Big Data Analytics and Decision Making, pp. 625-633.

Yang, T. and Hung, C.C. (2007), "Multiple-attribute decision making methods for plant layout design problem", Robotics and Computer-Integrated Manufacturing, Vol. 23 No. 1, pp. 126-137.

Application of fuzzy TOPSIS framework

Yazdi, A.K., Komijan, A.R., Wanke, P.F. and Sardar, S. (2020), "Oil project selection in Iran: a hybrid MADM approach in an uncertain environment”, Applied Soft Computing, Vol. 88 No. March.

\section{Further reading}

Arunachalam, R., Piya, S., Krishnan, P.K., Muraliraja, R., Christy, J.V., Mourad, A.H.I. and Al-Maharbi, M. (2020), "Optimization of stir-squeeze casting parameters for production of metal matrix composites using a hybrid analytical hierarchy process-Taguchi-Grey approach", Engineering Optimization, Vol. 52 No. 7, pp. 1166-1183.

Forés, B. and Camisón, C. (2016), "Does incremental and radical innovation performance depend on different types of knowledge accumulation capabilities and organizational size?", Journal of Business Research, Vol. 69 No. 2, pp. 831-848.

Büyüközkan, G. and Fethullah Göçer, F. (2017), "Application of a new combined intuitionistic fuzzy MCDM approach based on axiomatic design methodology for the supplier selection problem", Applied Soft Computing, Vol. 52, pp. 1222-1238.

Kivilä, J., Martinsuo, M. and Vuorinen, L. (2017), "Sustainable project management through project control in infrastructure projects", International Journal of Project Management, Vol. 35 No. 6, pp. 1167-1183.

San Cristóbal, J.R. (2017), “Complexity in project management”, Procedia Computer Science, Vol. 121, pp. 762-766.

Wang, T.C. and Lee, H.D. (2009), "Developing a fuzzy TOPSIS approach based on subjective weights and objective weights", Expert Systems with Applications, Vol. 36 No. 5, pp. 8980-8985.

Whyte, J., Stasis, A. and Lindkvist, C. (2016), "Managing change in the delivery of complex projects: Configuration management, asset information and 'big data", International Journal of Project Management, Vol. 34 No. 2, pp. 339-351.

\section{Corresponding author}

AHM Shamsuzzoha can be contacted at: ahsh@uwasa.fi 
JGOSS

Appendix

14,3

564

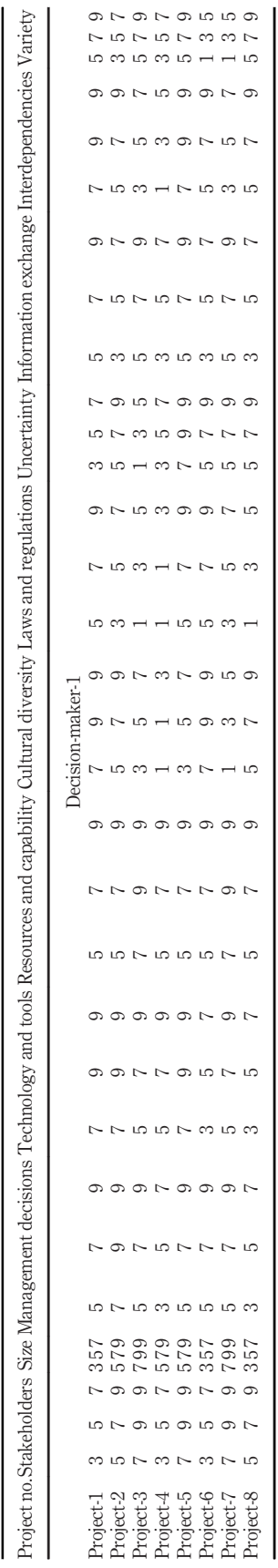

Table A1.

Display of opinions of group 1 decisionmakers from linguistic values to fuzzy numbers on project complexity factors. 


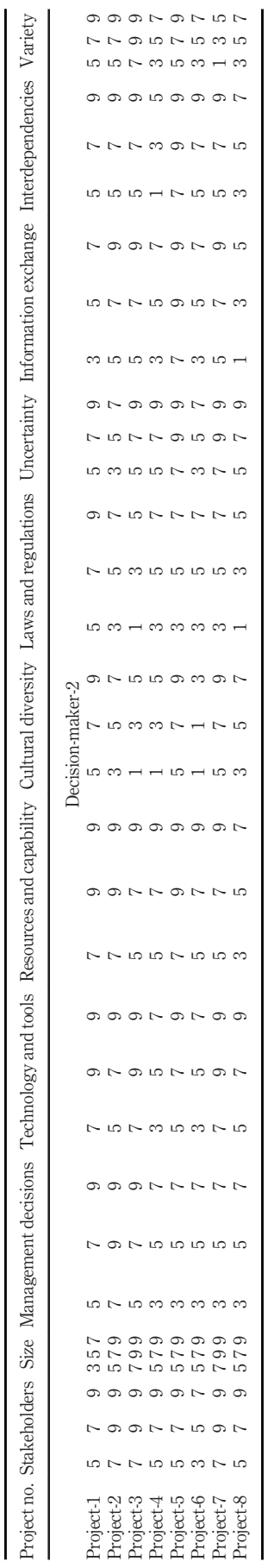

Application of fuzzy TOPSIS framework

Table A2.

Display of opinions of group 2 decisionmakers from linguistic values to fuzzy numbers on project complexity factors 
JGOSS

14,3

566

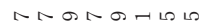

Table A3.

Display of opinions of group 3 decisionmakers from linguistic values to fuzzy numbers on project complexity factors 